\title{
TNFa is Involved in the Development of Disuse Muscle Atrophy Through the Acid Sphingomyelinase/ Ceramide Up-Regulation and Pro-Oxidant Signaling
}

Irina G. Bryndina ( $\sim$ i_bryndina@mail.ru )

Izhevsk State Medical Academy https://orcid.org/0000-0003-4099-4508

Natalia G. Ovchinina

Izhevsk State Medical Academy

Vladimir A. Protopopov

Izhevsk State Medical Academy

Alexey V. Sekunov

Izhevsk State Medical Academy

Maria N. Shalagina

Izhevsk State Medical Academy

\section{Research}

Keywords: disuse muscle atrophy, TNFa/TNFR1, aSMase, ceramide, NADPH oxidase, apoptosis

Posted Date: November 20th, 2020

DOI: https://doi.org/10.21203/rs.3.rs-111015/v1

License: (c) (i) This work is licensed under a Creative Commons Attribution 4.0 International License.

Read Full License 
$\mathrm{TNFa}$ is involved in the development of disuse muscle atrophy through the acid sphingomyelinase/ ceramide up-regulation and pro-oxidant signaling

Irina G. Bryndina ${ }^{1 *}$, Natalia N. Ovchinina ${ }^{1}$, Vladimir A. Protopopov ${ }^{1}$, Alexey V. Sekunov ${ }^{1}$, Maria N. Shalagina ${ }^{1}$

1 - Izhevsk State Medical Academy, Kommunarov St., 281, Izhevsk, 426034, Russia

* - corresponding author 


\begin{abstract}
Background: There is paucity of data indicating the role of cytokines including TNFa in the development of disuse muscle atrophy, despite the growing interest to this problem emerging in the recent years. The aim of the present study was to test the hypothesis that TNFa/ TNFR1 may be involved in the development of disuse muscle atrophy caused by unloading through aSMase/ ceramide/ ROS mechanism.
\end{abstract}

Methods: The experiments were performed on male Wistar rats $(180-230 \mathrm{~g})$ subjected to 4 or 14 days of hindlimb suspension (HS) and treated with clomipramine (HS+Clom) or vehicle. The following parameters were studied: TNFR1, aSMase, nSMase and Nox2 proteins and ceramide in detergent-resistant membrane (DRM) fraction isolated from soleus muscle homogenates, prooxidant/anti-oxidant and pro-apoptotic/anti-apoptotic activities, immune fluorescence intensity and distribution of ceramide, Nox2, Nox4 and caveolin-3 on longitudinal and transverse muscle sections. The relative muscle mass, cross-sectional area (CSA) and Feret's diameter (FD) of muscle fibers were used to confirm muscle atrophy. Statistical analysis was performed using one-way ANOVA followed by the Bonferroni post hoc test, or Cruskall-Wallis and MannWhitney U test.

Results: Disuse caused an increase in membrane TNFR1, aSMase, ceramide abundance in DRM, up-regulation of pro-oxidant and pro-apoptotic capacities (increased Nox2, Nox4, TBAactive products, Bax/Bcl-2 ratio, elevated activity of caspase-3/7 and -6 ). The most of alterations were maximal on the $4^{\text {th }}$ day of unloading. The inhibitor of aSMase clomipramine attenuated ceramide accumulation, decreased pro-oxidant and pro-apoptotic activities and diminished muscle atrophy induced by unloading. It has been shown that in suspended for 14 days rats the loss in relative muscle mass, CSA and FD averaged $-35 \%,-65 \%$ and $-49 \%$, respectively, whereas in clomipramine treated rats it was $-25 \%,-45 \%$ and $-25 \%$, in comparison with the control values. Clomipramine also mitigated the inhibition of the mTORC1/p70S6 kinase inhibition caused by 14-day HS.

Conclusions: The obtained results indicate the involvement of aSMase/ ceramide pathway in the development of disuse muscle atrophy. This effect may be triggered by TNFR1 and realized through enhanced prooxidant NADPH oxidase activity and pro-apoptotic signaling.

Keywords: disuse muscle atrophy, TNFa/TNFR1, aSMase, ceramide, NADPH oxidase, apoptosis 


\section{Background}

There is considerable evidence of cytokine, particularly tumor necrosis factor alpha (TNFa), involvement in the development of muscle atrophy due to severe pathologies like sepsis, COPD, cardiac failure, cancer and others $[1,2]$. The data indicating the roles of cytokines including $\mathrm{TNFa}$ in disuse muscle atrophy are very few, despite the growing interest to this problem emerging in the recent years. TNFa contribution to disuse muscle atrophy was described in a number of works [3-8].

TNF-alpha was moderately down-regulated in soleus muscle of rats exposed to hindlimb suspension (HS) for 7 days [3]. In contrast, the other group of authors [4] described the increase in TNFa abundance in unloaded rat soleus muscle from the $3^{\text {rd }}$ until $14^{\text {th }}$ day of HS. An elevation of TNFa, IL-1beta and IL-6 was also observed in rat soleus muscle disused for $14^{\text {th }}$ days [5]. We have shown previously that TNFa is not up-regulated after 12-hour muscle unloading, whereas the expression of its receptor TNFR1 in detergent-resistant membranes (DRM) is increased more than 3-fold [6]. A group of authors [7] using a model of 14-day hindlimb immobilization in Wistar rats have demonstrated the elevated plasma and muscle TNF- $\alpha$ levels along with oxidative stress and NF-kB signaling activation. The other authors [8] obtained the similar results in human: TNF- $\alpha, \mathrm{NF}-\kappa \mathrm{B}$, myostatin, ubiquitin and calpain mRNA were over-expressed after 28-day lower-limb immobilization.

TNFa is the first historically described proinflammatory cytokine of TNF family [9]. The main sources of $\mathrm{TNFa}$ production are the cells of both innate and adaptive immunity, like macrophages, NK cells, T-lymphocytes, mast cells and endothelial cells. TNFa is known to produce multiple effects in different target cells throughout the body including skeletal muscle. Moreover, there is a body of evidence which points to TNFa expression in skeletal muscle cells along with other myokines [10].

TNFa excerts its effects through two types of membrane receptors, TNFR1 and TNFR2. TNFR1 is known as inducer of skeletal muscle wasting, whereas TNFR2 has the opposite effect $[11,12]$. The main subsequences of TNFR1 activation in skeletal muscles are apoptosis, contractile disability, inflammation and endothelial dysfunction [2].

Currently available data do not provide a complete understanding of TNFa impact upon the mechanisms of muscle atrophy and dysfunction during unloading. For instance, the involvement of sphingolipid mechanisms in TNFa effects induced by disuse has not been elucidated. Meanwhile, according to the results obtained to-date, TNFa/TNFR1 may act through recruitment 
and activation of both acid and neutral sphingomyelinases (aSMase, nSMase). These enzymes hydrolyze sphingomyelin and therefore lead to the enhanced abundance of intracellular and plasma membrane ceramide [13-18]. We have demonstrated that the sarcolemmal ceramide pool is increased in disused rat soleus muscle, and this mechanism may apparently be responsible for lipid rafts disassembly due to short-term hindlimb unloading [6, 19]. Interestingly, we have established that in the early period of HS, TNFR1 expression in DRM isolated from the unloaded muscle is up-regulated [6], and this phenomenon precedes TNFa increase in muscle shown to be developed only on the $3^{\text {rd }}$ day of HS [4].

Among the key pathways involved in TNF- $\alpha$-induced impairment of skeletal muscle functions are the following: inhibition of protein synthesis, accelerating protein degradation, increased production of reactive oxygen species (ROS), activation of apoptosis, down-regulated expression of genes involved in myogenesis and regeneration [1, 20-25]. There is evidence that both TNFa and sphingomyelinases/ceramide promotes ROS generation [17]. Furthermore, contractile dysfunction, a characteristic feature of skeletal muscle disuse [26], may be induced by sphingomyelinases and realized through activation of NADPH oxidase [27]. In this case, one of the possible mechanisms is formation of ceramide-enriched membrane platforms which are able to cluster the components of NADPH oxidase complex, thereby facilitating its assembling and activation $[28,29]$. It should be noted that oxidant activity is known to be involved in the development of disuse muscle atrophy [30, 31].

Taking into account all mentioned above, we hypothesized that TNFa/ TNFR1/ SMase/ ceramide mechanism is involved in the development of the disuse muscle atrophy, and aSMase inhibitor clomipramine treatment is able to attenuate atrophy caused by two-week unloading.

\section{Methods}

\section{Animals and experimental protocol}

The aim of the present work was to estimate TNFR1, pro-oxidant capacity and atrophic changes in rat soleus muscle exposed to the 4- or 14-day unloading, and dependence of those changes on activation of aSMase.

All experiments were performed on adult male Wistar rats $(180-230 \mathrm{~g})$. The research conforms to the Guide for the Care and Use of Laboratory Animals (NIH Publication No. 85-23, revised 1996) and European Convention for the Protection of Vertebrate Animals used for Experimental and other Scientific Purposes (Council of Europe No 123, Strasbourg, 1985). The experimental protocol met the requirements of the EU Directive 2010/63/EU and was approved by the Bioethics Committees of Izhevsk State Medical Academy. 
In our experiments, hindlimb suspension (HS) model was used as a well-studied and most suitable method to simulate muscle unloading $[32,33]$. Rats $(n=30)$ subjected to HS in individual cages with free access to food and water were able to move in all directions using their forelimbs with the lacking support afferentation of suspended hindlimbs.

For the experiments, five groups of rats were used: 1$)$ the $1^{\text {st }}$ group consist of freely moving nontreated rats served as a vivarium control (C) group $(n=6) ; 2$ ) rats suspended for 4 days (4d HS) and 14 days ( $14 \mathrm{~d}$ HS) formed the $2^{\text {nd }}$ and the $3^{\text {rd }}$ groups ( $\mathrm{n}=6$ for both); 3 ) the $4^{\text {th }}$ and the $5^{\text {th }}$ groups included suspended for 4 or 14 days rats treated with the inhibitor of acid SMase clomipramine (4d HS+Clom, 14d HS+Clom). Clomipramine (Anafranil, Novartis Pharma AG, intramuscularly, $1.25 \mathrm{mg} / \mathrm{g}$ body weight) was administered every other day during the whole experiment ( 4 or 14 days, $n=6$ for both). The animals from the $2^{\text {nd }}$ and $3^{\text {rd }}$ groups (suspended non-treated rats) were injected with vehicle $(0.9 \%$ saline solution in equal amounts and according to the same regimen). After the end of HS rats were immediately anesthetized with an intramuscular injection of Zoletil 50 (0.1 ml, Virbac, France). Animals were divided into two groups which were prepared for biochemical or immunofluorescence study.

For biochemical assay, soleus muscles were harvested, weighed, quickly frozen in liquid nitrogen, and stored at $-80^{\circ} \mathrm{C}$. For immunofluorescent study, animals were perfused through the ascending aorta with phosphate-buffered saline (PBS in mM: 3.2 NaH2PO4, 0.5 K2HPO4, 1.3 $\mathrm{KCl}, 135 \mathrm{NaCl}, \mathrm{pH} 7.4$ ), and then with 4\% parapharmaldehyde prepared with PBS. Soleus muscles were postfixed in the same fixative for 2 hours, transferred to a $30 \%$ sucrose solution for a day and then frozen on dry ice.

\section{Isolation of detergent-resistant membrane fraction from muscle homogenates}

Isolation of DRM was performed according to earlier described method [34]. The samples of muscle tissue $(10 \mathrm{mg})$ were homogenized in $1 \mathrm{ml}$ of lysing TBS buffer (1\% Triton X-100 in 25 $\mathrm{mM}$ Tris / $\mathrm{HCl}+140 \mathrm{mM} \mathrm{NaCl}+$ protease / phosphatase inhibitors, $\mathrm{pH}$ 7.5) with IKA T10 Basic Ultra Turrax Homogenizer. The homogenates were incubated at $+4^{\circ} \mathrm{C}$ for 30 minutes. The obtained lysates were mixed with $2 \mathrm{ml}$ of $60 \%$ sucrose in TBS $(25 \mathrm{mM}$ Tris $/ \mathrm{HCl}+140 \mathrm{mM}$ $\mathrm{NaCl}, \mathrm{pH} 7.5$ ), then sucrose (TBS) was added layer-by-layer in order of $1 \mathrm{ml}$ of $30 \%$ solution and $1 \mathrm{ml}$ of $5 \%$ one. The samples were centrifuged at $300000 \mathrm{~g}$ for 3 hours at $+4^{\circ} \mathrm{C}$, and then 0.6-1.0 $\mathrm{ml}$ of the top fraction was collected and analyzed.

Ganglioside GM1 in isolated DRM containing fraction was used as a raft marker. For GM1 detection, chloroform extracts prepared from the DRM containing fraction were developed on HPTLC Silica gel 60 F$_{254}$ plates (Merck, Germany) with GM1 standard (Avanti polar lipids, USA) in propanol:water 7:3 solvent system as described earlier [35, 36]. 


\section{TNFR1, sphingomyelinases, Nox2, Bax and Bcl-2 assays}

Bax and Bcl-2 were assessed in homogenates of muscle tissue. TNFR1, aSMase, nSMase, Nox2 were assessed in DRM isolated from muscle homogenates by centrifugation in sucrose gradient. All proteins were detected by Western blot analysis as described previously [6] Briefly, muscle homogenates or DRM fraction from the sucrose gradient $(25 \mu 1$, concentration of total protein $10-15 \mathrm{mg} / \mathrm{ml}$ ) were analyzed by SDS/PAGE as described by [37] on a $10 \%(\mathrm{w} / \mathrm{v})$ acryl amide gel (Mini-Protean ${ }^{\circledR}$, Bio-Rad). Proteins from the gel were then transferred onto a nitrocellulose membrane for immunoblot analysis (Mini Trans-Blot ${ }^{\circledR}$, Bio-Rad). Membranes were incubated overnight with diluted primary antibodies in 5\% (w/v) BSA in 1x TBS-Tween 20 $\left(0.1 \%(w / v)\right.$ Tween 20 in $10 \mathrm{mM}$ Tris, $\mathrm{pH} \mathrm{7.5)}$ at $4^{\circ} \mathrm{C}$ with shaking. Primary antibodies were the following: anti-aSMase (1:300, ThermoFisher), anti-nSMase (1:1000, Abcam, USA), antiTNFR1 (1:100, Abcam, ), anti-NOX2 (1:1000, Abcam,), anti-Bax (1:1000, Abcam) and antiBcl-2 (1:500, Abcam). HRP-conjugated goat anti-rabbit IgG antibodies (1:20000, Abcam) were added and incubated for 60 minutes at room temperature. Membranes were then exposed using the 3,3'-diaminobenzidine (DAB) detection and obtained images were analyzed by ImageJ tool kit.

\section{Ceramide assay in DRM isolated from the soleus muscle}

Ceramide in DRM was assessed by high performance thin-layer chromatography (HPTLC) as described previously (Petrov et al., 2019). For the assay, lipids were extracted from the DRM fraction with Folch reagent (chlorophorm:methanol, 2:1) [35] and processed as described [36]. Chloroform extracts $(0.1 \mathrm{ml})$ were spotted on HPTLC Silica gel $60 \mathrm{~F}_{254}$ plates (Merck, Germany) and developed in the butanol:acetic acid:water, 3:1:1 solvent system according to [38] together with the equivalent volume of the standard chloroform ceramide solution (Avanti polar lipids, USA). Plates were then imaged by iodine vapor and analyzed by video-densitometer (Sorbfil, Russia) at UV light $(254 \mathrm{~nm})$. Analysis of ceramide was performed with Sorbfil TLC Videodensitometer software (Sorbpolymer, Russia). The values of standard samples of ceramide were used for calculation of ceramide content.

\section{Immunofluorescence study of ceramide, Nox2, Nox4, Bax, Bcl-2, and caveolin-3}

For the immunofluorescent staining of Nox2, Nox4 and caveolin-3 in the soleus muscle, serial longitudinal and transverse muscle sections $(14 \mu \mathrm{m})$ were made using Shandon Cryotom E (UK) or HM525 NX Cryostat (Thermo Fisher Scientific, USA). The sections were mounted on the Superfrost Plus slides (Thermo Fisher Scientific, USA). Immunofluorescent staining was 
performed as described previously [6]. Before staining, sections were kept for 10 minutes in 3\% hydrogen peroxide. After washing in PBS, the sections were incubated for 2 hours in 5\% BSA solution. After that, muscle sections were incubated with anti-ceramide antibodies (mouse IgG, 1:300, Enzo Life Sciences, USA), anti-Nox2, anti-Nox4 (both rabbit IgG, 1:300, Abcam), and anti-caveolin-3 (rabbit IgG,1:200, Abcam) antibodies for 24 hours at room temperature. The second antibodies associated with Alexa Fluor 488 for caveolin-3 and NOX-4, or anti-rabbit biotinylated antibodies (goat IgG, 1:200) and FITC (1:100) for NOX-2 and ceramide, were used to visualize the antigens studied. The analysis of images made with the Canon PowerShot 600 photo attachment combined with a Nikon Eclipse E200 microscope was performed using ImagePro Plus 6.0 morphometric program and ImagePro Insight program (Media Cybernetics, USA). The expression levels of immunoreactive ceramide and proteins were estimated by the intensity of the fluorescence of the investigated slice on a standard area $\left(0.1 \mathrm{~mm}^{2}\right)$. Every 5 th section of the organ was taken and 10 intensity measurements were made (at least 150 measurements per animal). Mean values were presented in arbitrary units of gray intensity of binary images used by the mentioned program.

\section{Detection of oxidant and anti-oxidant capacity in muscle homogenates}

To assay the oxidant activity in unloaded soleus muscle, we used a simple method detecting malondialdehyde (MDA), as one of the end products of lipid peroxidation, in reaction with thiobarbituric acid (TBA) (Agat, Russia). [39, 40]. Simultaneously, the activity of antioxidant enzymes was assayed in homogenates of muscle tissue. Catalase, superoxide dismutase (SOD) and glutathione peroxidase (GPx) were detected by the commercial kits (Abcam). All studies were performed according to the manufacturer's recommendations.

\section{Detection of caspase-3/7 and caspase- 6 activity}

Caspase-3/7 activity was measured with a commercially available colorimetric assay kit (Abcam). This kit is intended for assaying the DEVD-dependent caspase activity and is based on detection of DEVD-AFC (AFC: 7-amino-4-trifluoromethyl coumarin) substrate cleavage. Due to the nature of the substrate, the method detects both caspase- 3 and -7 activities. Caspase- 6 activity was detected using colorimetric caspase-6 assay kit (Abcam). All procedures were performed according to the manufacturer's instructions.

\section{Soleus muscle atrophy}

The atrophic changes in soleus muscle were studied by the measuring of the relative muscle mass and evaluation of its morphological features in control rats and in 14-day suspended 
animals administered with clomipramine or vehicle. The relative muscle mass was calculated as a ratio of muscle wet weight to body weight (mg/100п). Morphometric analysis was made with the ImagePro Insight program (Media Cybernetics, USA) by measuring the cross-sectional areas (CSA) and Feret's diameter of muscle fibers on the transverse sections of muscle stained with anti-caveolin-3 antibodies/ Alexa Fluor 488.

\section{Statistics}

Statistical analysis was performed using Origin Pro software and Statistica 6.0. Data in the text are presented as mean \pm SEM. Depending on the distribution, statistical significance of the differences between group means was evaluated using one-way ANOVA followed by the Bonferroni post hoc test, or Mann-Whitney $\mathrm{U}$ test. Values of $\mathrm{P}<0.05$ were considered significant.

\section{RESULTS}

\section{TNFR1 and sphingomyelinases in DRM isolated from the muscle homogenates}

In our previous work we have demonstrated a 3.8-fold enhancement of TNFR1 in DRM fraction of soleus muscles unloaded for 12 hours [6]. A considerable growth of TNFR1 was also found in the present study: it averaged 14-fold $(\mathrm{p}=0.004)$ and 15-fold $(\mathrm{p}=0.01)$, respectively, in DRMs of soleus muscles unloaded for 4 and 14 days (fig.1). No difference in TNFR1 availability in DRM of unloaded muscles was detected between these two groups of suspended animals.
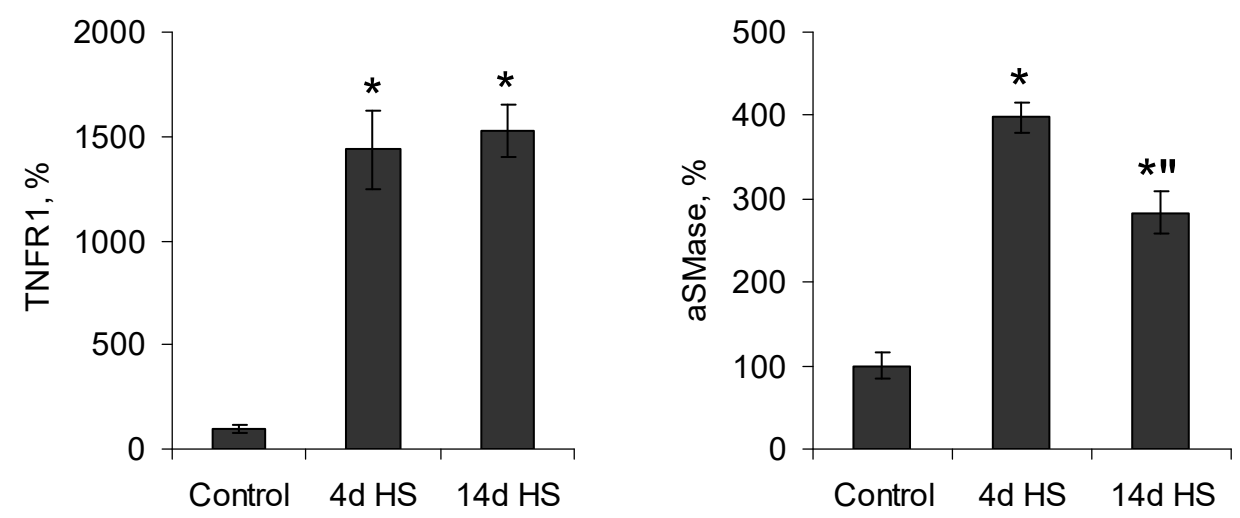

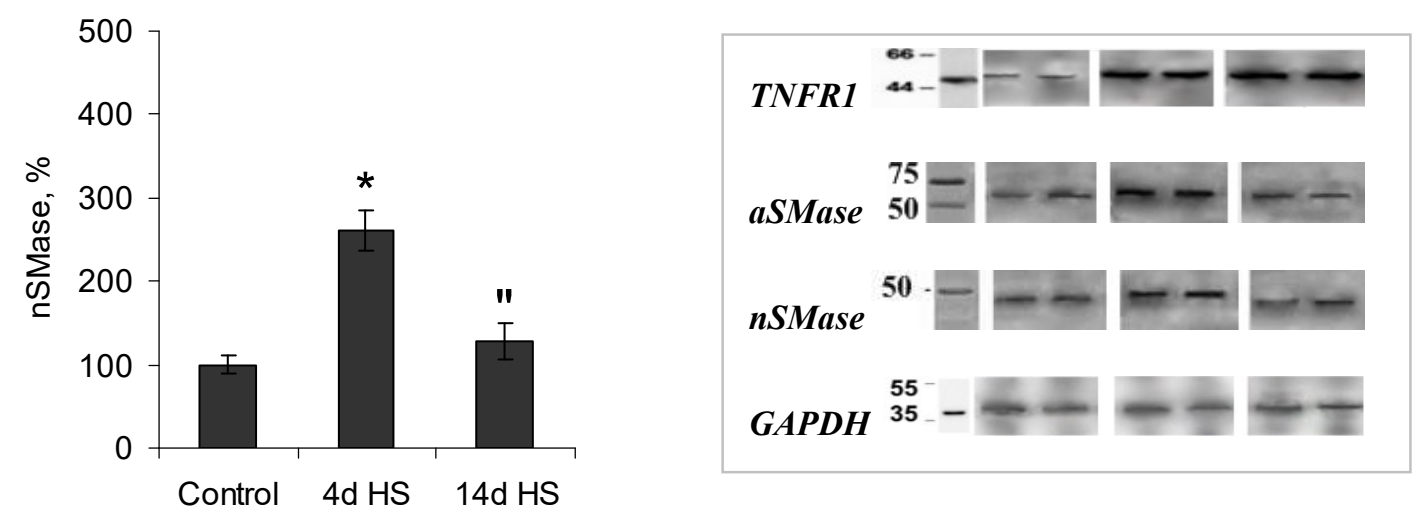

Figure 1. 4-day and 14-day hindlimb suspension leads to the increase in abundance of TNFa receptor (TNFR1) with concomitant aSMase and nSMase elevation in detergent-resistant membrane fraction isolated from the rat soleus muscle homogenates (Western blot).TNFR1, aSMase increased at both 4 th and $14^{\text {th }}$ days of HS; nSMase increased only at the $4^{\text {th }}$ day. * - $\mathrm{p}<0.05$ - significant difference in comparison with control, " - significant difference between the $4^{\text {th }}$ and $14^{\text {th }}$ days of HS

Both aSMase and nSMase were increased in the raft fraction, too. For instance, aSMase enhanced about 4 -fold by the $4^{\text {th }}$ day $(\mathrm{P}=0.004)$ and about 3 -fold by the $14^{\text {th }}$ day of unloading $(\mathrm{P}=0.01)$. The increased nSMase amount was detected only on the $4^{\text {th }}$ day $(2.6-f o l d, P=0.004)$. Significant differences in aSMase and nSmase growth were revealed between two groups of animals which were suspended for 4 or 14 days $(p=0.016)$.

\section{Ceramide (biochemical and immunofluorescence study)}

We have shown previously that lipid raft disorganization in rat soleus muscle caused by shortterm unloading (12 hours) is associated with aSMase/ceramide up-regulation [6, 19]. Also, we have demonstrated that not only ceramide amount but its distribution in muscle fibers substantially renders during disuse [41]. In the present work, we studied the intensity and distribution of ceramide immunofluorescence in longitudinal sections of rat soleus muscle that underwent 4- or 14-day unloading with or without clomipramine treatment.

In this experiment we obtained the following results. Both 4- and 14-day unloading led to the considerable increase in ceramide immunofluorescence with the parallel reorganization of ceramide-containing structures throughout the fibers (fig. 2). While in the control animals ceramide staining was characterized by the weak diffuse fluorescence, located preferentially in the region of the plasma membrane, in unloaded muscle this image was very different. Ceramide accumulated in the form of large superficial structures resembled ceramide-enriched membrane domains described earlier by [28] and found by us in rat soleus muscle suspended for 4 days [41]. Clomipramine treatment was effective in partial prevention of ceramide membrane 
rearrangement due to disuse. Interestingly, WB analysis of ceramide amount in DRM demonstrated that it changed similarly to aSMase: the maximal growth of ceramide occurred on the $4^{\text {th }}$ day of unloading $(6.8$-fold, $\mathrm{p}=0.010)$.

A
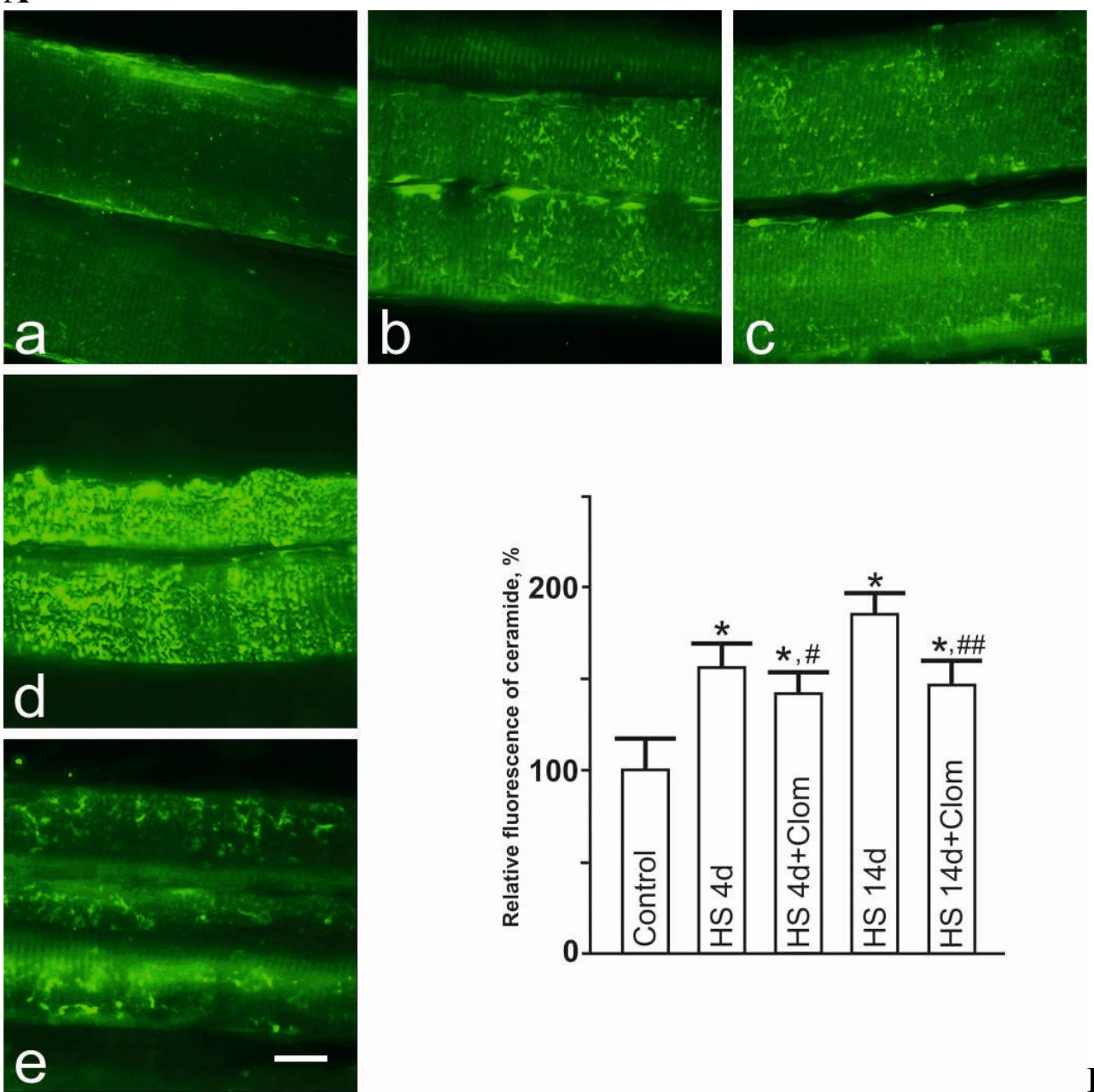

$\mathbf{C}$

D
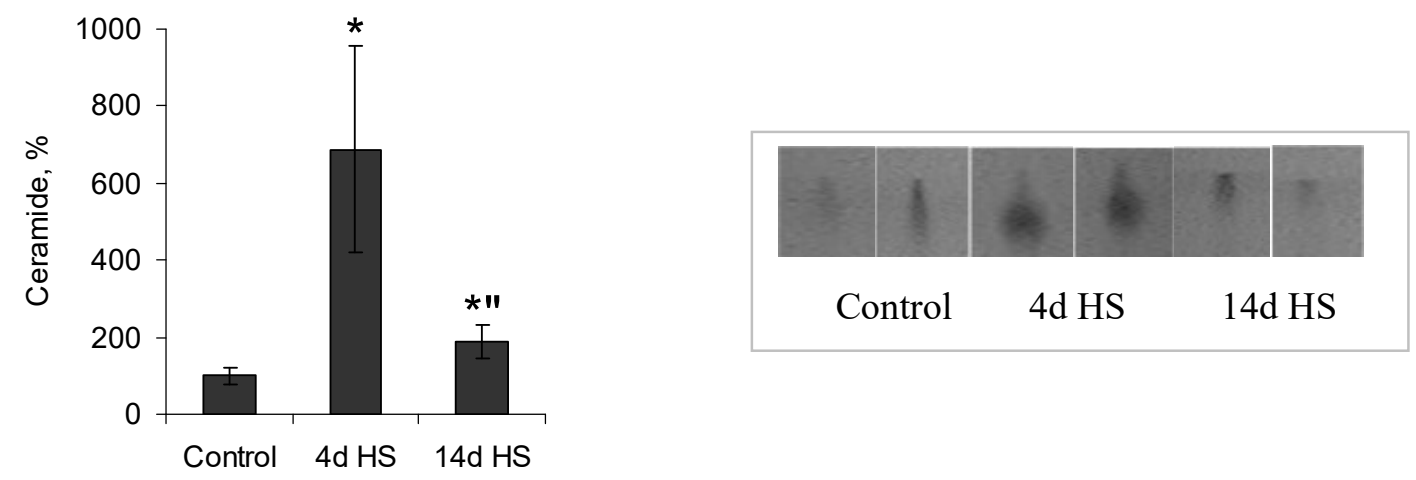

Figure 2. Ceramide is up-regulated in rat soleus muscle unloaded for 4 and 14 days. Immunofluorescence staining of ceramide on longitudinal sections of muscle fibers revealed the increase in ceramide abundance and formation of peculiar membrane structures looking like 
ceramide-enriched membrane domains: $\mathbf{a}$-control, $\mathbf{b}$-4-day HS with vehicle, $\mathbf{c}-4$-day HS with clomipramine treatment; $\mathbf{d}$ - 14-day HS with vehicle, $\mathbf{e}$-14-day HS with clomipramine treatment; line length $=10 \mathrm{mcm}$ (A) Quantification of ceramide levels in unloaded for 4 and 14 days soleus muscle: the effect of clomipramine treatment. Clomipramine partly prevents ceramide up-regulation in the unloaded muscle (B) Ceramide in detergent-resistant membrane fraction (DRM) of soleus muscle homogenates; $\mathbf{C}$ - ceramide in DRM (\%, HPTLC); D ceramide spots in chromatograms, ${ }^{*} \mathrm{p}<0.05$ - significant difference in comparison with control, \# $\mathrm{p}<0.05$ - significant difference between the $14 \mathrm{~d} \mathrm{HS}$ and $14 \mathrm{~d} \mathrm{HS}+\mathrm{Clom}, " \mathrm{p}<0.05$ - significant difference between the 4-day and 14-day HS

\section{Pro-oxidant and anti-oxidant capacity}

\section{Nox2 and Nox4}

Skeletal muscle expresses three isoforms of NADPH oxidases (Nox1, Nox2, and Nox4) which are considered to be the main source of ROS [42].

In our experiment, we assayed Nox 2 and Nox4 isoforms of NADPH oxidase in disused skeletal muscle. The results obtained in the WB study demonstrated that Nox 2 protein abundance in DRM of unloaded muscle was 2.2-fold $(\mathrm{P}=0.004)$ and 1.4-fold $(\mathrm{P}=0.01)$ higher than in the control animals on the $4^{\text {th }}$ and $14^{\text {th }}$ days of HS, respectively. Interestingly, the dynamics of Nox 2 changes in DRM coincided with that of aSMase and ceramide: the maximal growth of NOX2 was achieved by the $4^{\text {th }}$ day of HS (fig.3).

In the immunofluorescence study, we obtained the similar results: Nox 2 abundance enhanced by $73.5 \%(\mathrm{p}<0.001)$ in soleus muscles of the animals suspended for 4 days. The elevation of Nox 2 amount was found also on the $14^{\text {th }}$ day of unloading. The inhibitor of aSMase clomipramine partly prevented Nox2 up-regulation (fig. 3). 

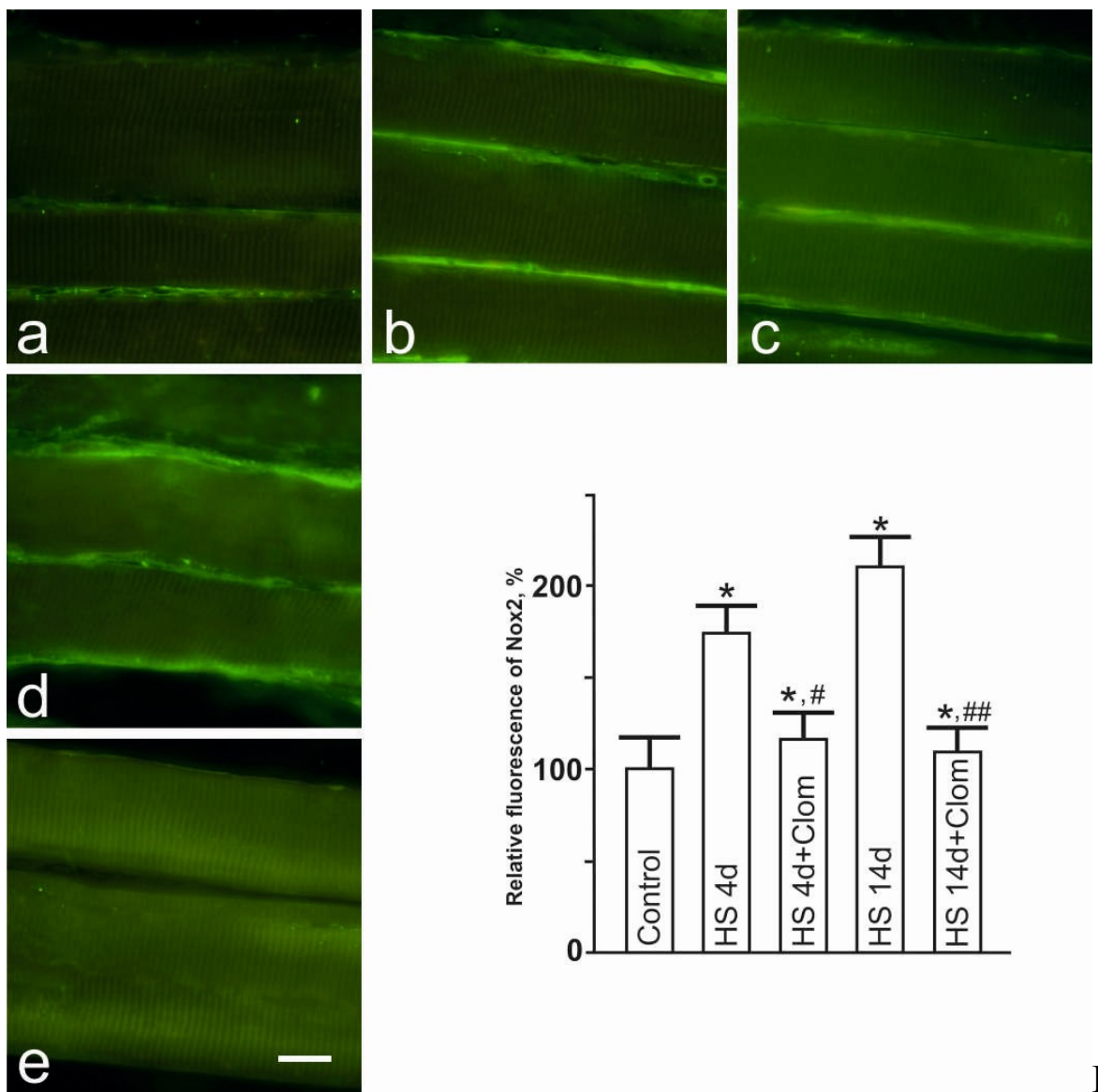

\section{B}

C

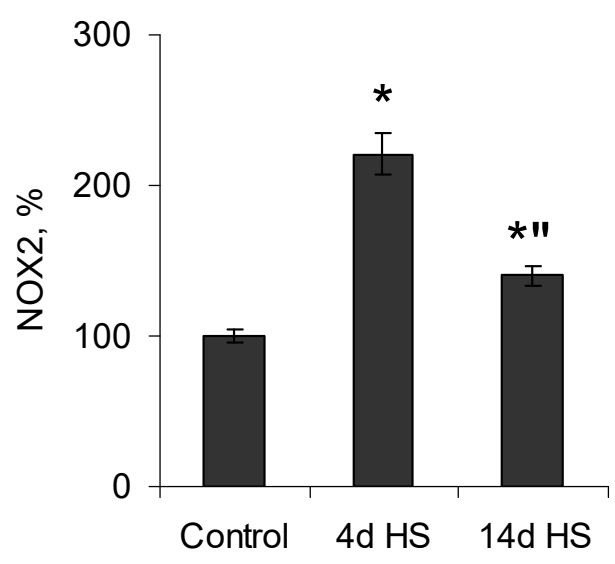

D

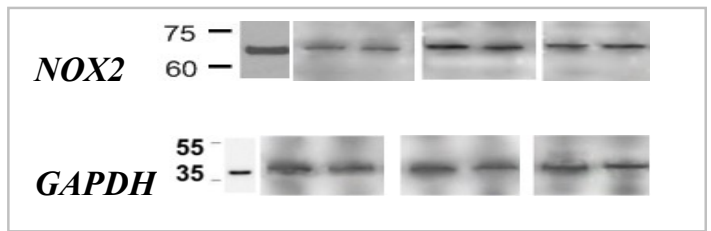

Figure 3. Up-regulation of NOX2 immunoreactivity in rat soleus muscle subjected to for 4- or 14-day unloading is partly prevented by clomipramine treatment: $\mathbf{a}$ - control, $\mathbf{b}$-4-day HS with vehicle, $\mathbf{c}$-4-day HS with clomipramine treatment; $\mathbf{d}$ - 14-day HS with vehicle, $\mathbf{e}$ - 14-day HS with clomipramine treatment; line length $=10 \mathrm{mcm}(\mathbf{A})$. Quantitative analysis of NOX2 levels in suspended for 4 or 14 days soleus muscle in rats treated with clomipramine (Clom) or vehicle (B). NOX2 in detergent-resistant membrane fraction (DRM) detected by WB, in \% to the control value $(\mathbf{C}) ;{ }^{*} \mathrm{p}<0.05$ - significant difference in comparison with control, " $\mathrm{p}<0.05$ - between the $4^{\text {th }}$ and $14^{\text {th }}$ days. 
Nox4 is known to localize to the plasma membrane, the inner mytochondria membrane, SPR and transverse tubules of skeletal muscles fibers [43, 44, 45]. In accordance with this, Nox4 staining in our experiments with 14-day muscle unloading was revealed in both sarcolemmal and sarcoplasmic regions. HS led to a substantial increase in Nox4 fluorescence density and intensity in muscle fibers (by $76.3 \pm 20.1 \%, \mathrm{p}<0.05$ ). Substances immunopositive to this protein were detected as small separated granules or large merged structures localized both in sarcolemmal regions and intracellular compartments (fig.4). Visually, more intensive staining was found in the plasma membrane regions, although the background fluorescence was also increased. Interestingly, the signal was not continuous and looked like separated spots outlining the membrane. Clomipramine administration reduced the intensity of Nox4 fluorescent signal in the unloaded muscle by $47.8 \pm 6.5 \%(\mathrm{p}<0.05)$ in comparison with the animals suspended with vehicle. However, the level of immunoreactive staining in the soleus muscle of individuals treated with clomipramine exceeded the control value by $19.3 \%(p<0.05)$. Interestingly, clomipramine considerably rendered not only expression but also distribution of Nox4 in muscle fibers of treated rats.
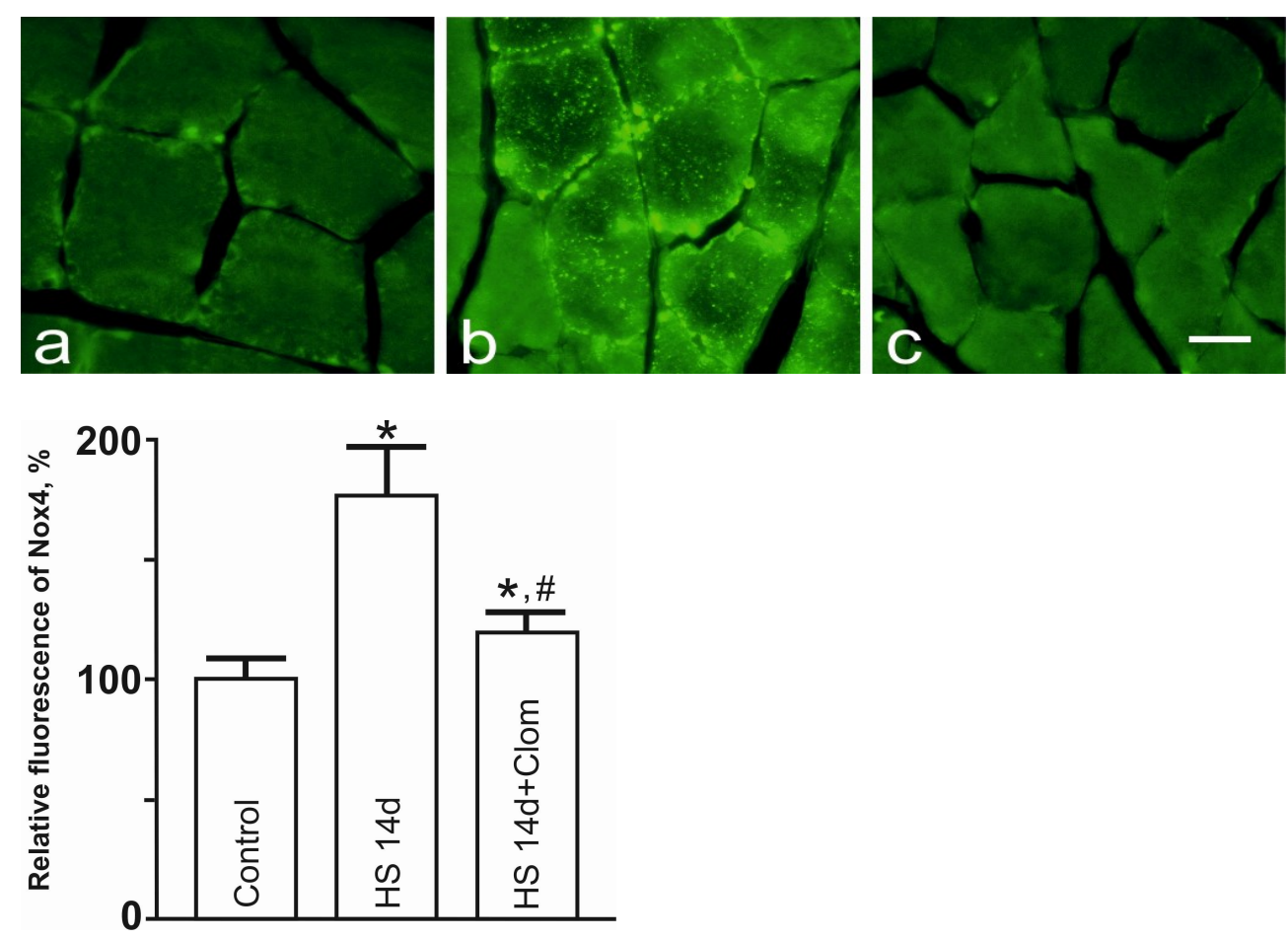

Figure 4. Hindlimb suspension (14 days) considerably alters the intensity and distribution of the Nox 4 immune staining on the transverse sections of rat soleus muscle. Immunofluorescence is enhanced in the plasma membrane and intracellular compartments of muscle fibers.

Clomipramine treatment decreases Nox 4 abundance and rearranges its distribution. a - control, b - 14-day HS + vehicle, c - 14-day HS + clomipramine; * - $<<0.05$, in comparison with control value, $\#-p<0.05$, in comparison with HS. 


\section{TBA-active products and antioxidant activity}

Taking into account that both Nox 2 and Nox 4 act as pro-oxidant factors, we simultaneously estimated the level of TBA-active products and the activity of antioxidant enzymes like catalase, SOD and GPx in unloaded soleus muscle (fig. 5). The obtained results indicated the increased pro-oxidant activity in muscle homogenates: TBA-active products were elevated more than 3fold by the $4^{\text {th }}$ day of HS ( $\left.\mathrm{p}=0.008\right)$, and did not differ from the control level on the $14^{\text {th }}$ day. SOD and GPx activity stayed unchanged after the $4^{\text {th }}$ day of the disuse, although catalase activity became $22 \%$ lower than in the control group $(\mathrm{p}=0.01)$. Interestingly, TBA-active products was mostly elevated after 4-day muscle unloading, and the dynamics of their changes coincided with that of aSMase, nSMase and ceramide, as well as the changes of Nox2 in DRM (fig. 1, 2, 3).
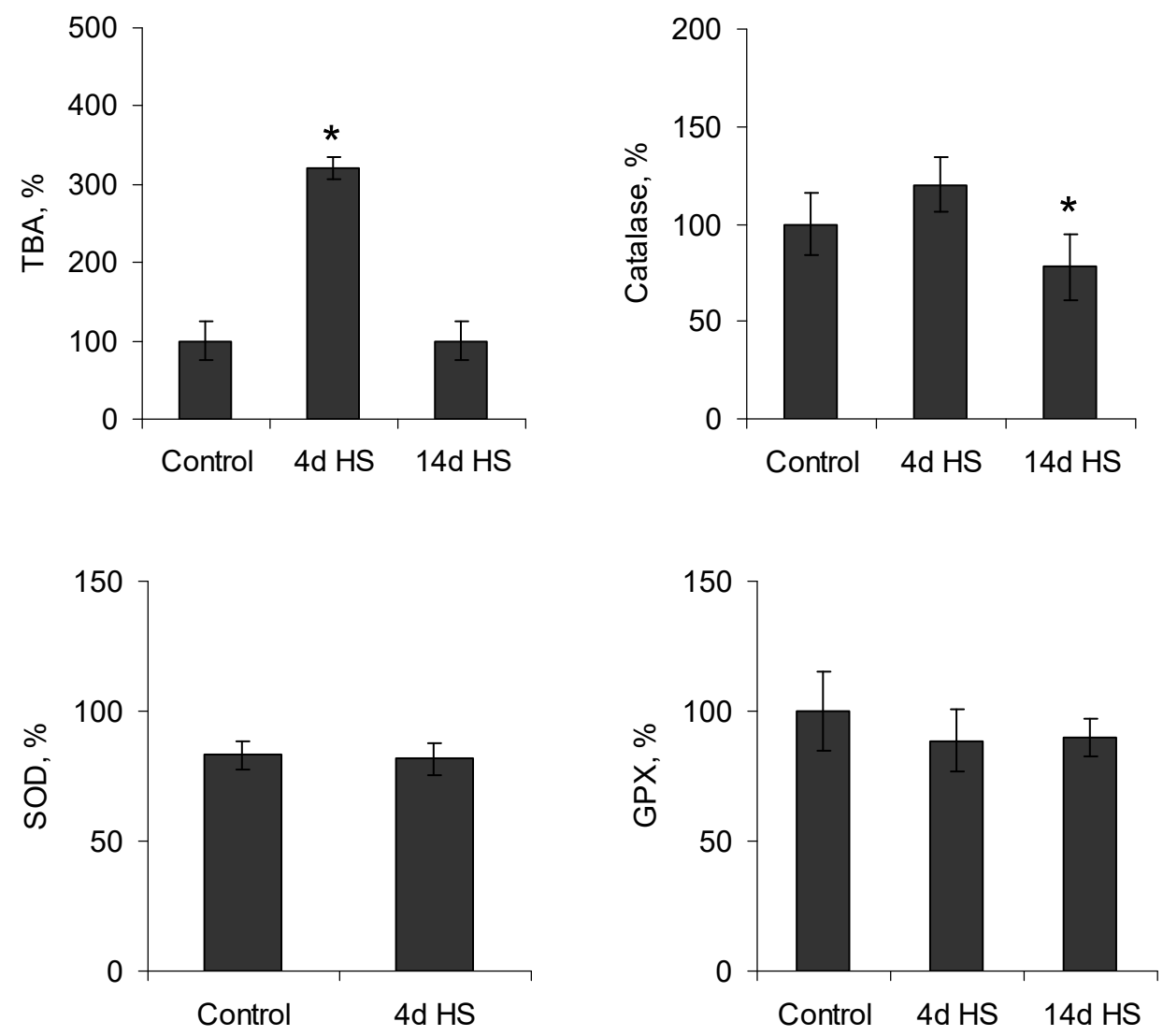

Figure 5. TBA-active products increase in rat soleus muscle after the 4-day unloading. Superoxide dismutase (SOD) and glutation peroxidase activities (GPx) did not change; catalase activity decreased in the muscle of rats subjected to 14-day HS; * $-\mathrm{p}<0.05$ in comparison with the control values.

\section{Muscle atrophy}

Soleus muscle atrophy due to disuse was studied at the $14^{\text {th }}$ day of unloading. The atrophy was confirmed by the loss of the muscle mass, decreased CSA and the diameters of muscle fibers 
(fig. 6). The relative muscle mass declined by $35 \%$ in comparison with the control value $(p=0.001)$, CSA and Feret's diameters of muscle fibers were decreased by $65 \%$ and $49 \%$, respectively $(\mathrm{p}<0.05)$. Clomipramine treatment partly prevented the loss of muscle mass and the morphological features of atrophy. The ratio muscle weight/ body weight exceeded the HS value by $14.5 \%$ ( $=0.008)$, although remained less by $25 \%$ than in control animals, CSA and Feret's diameters of muscle fibers decreased by $45 \%$ and $24 \%$ (all $\mathrm{p}<0.05$ ), respectively, in comparison with the control values.
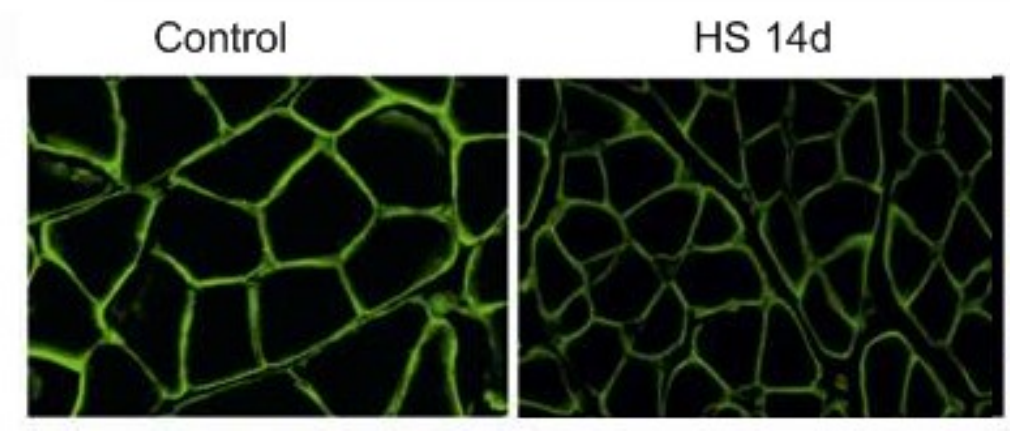

\section{HS $14 d+$ clom}
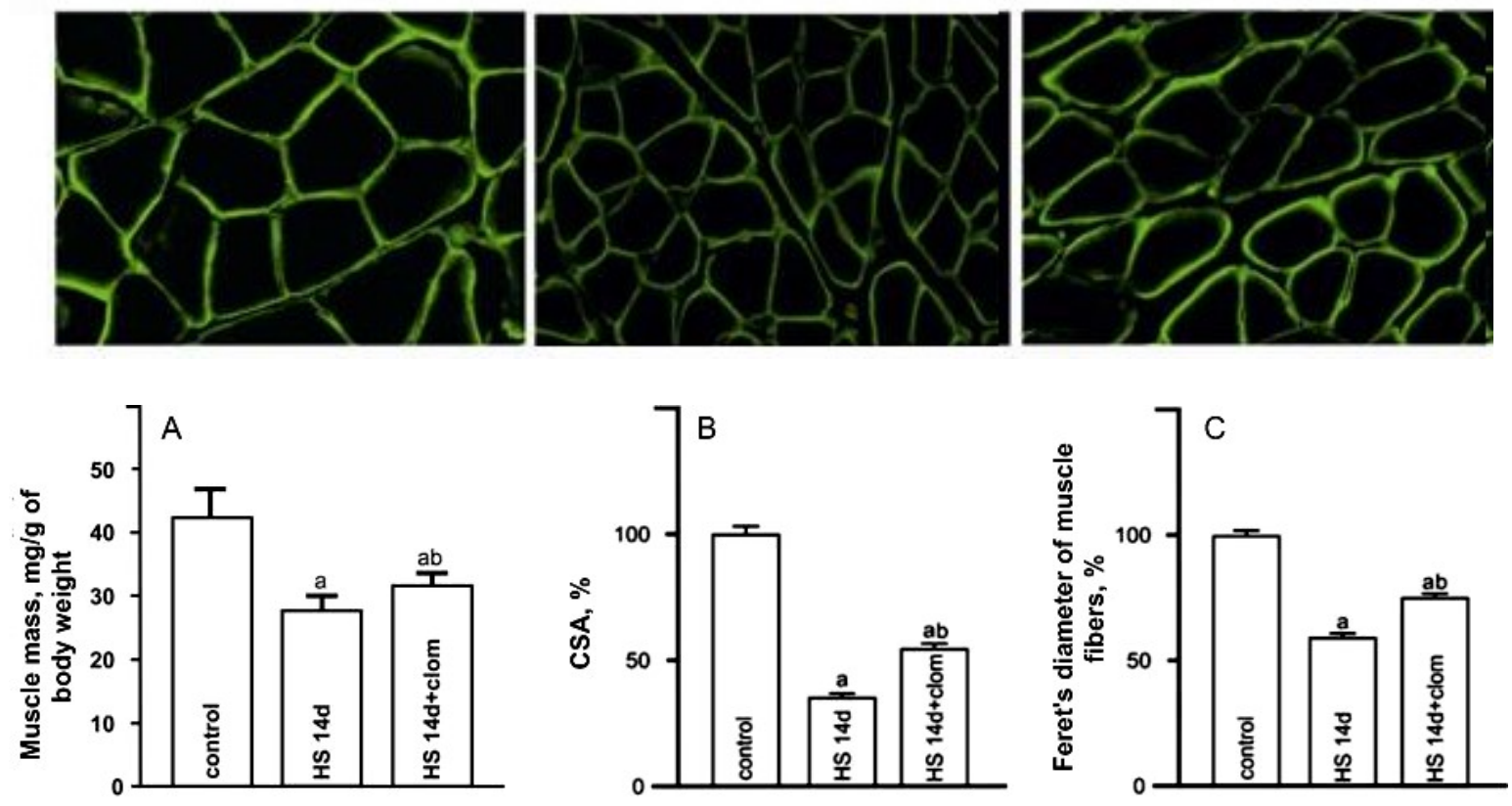

Figure 6. Loss of soleus muscle mass (A), decrease in cross-sectional area (CSA) and Feret's diameter (FD) of muscle fibers $(\mathbf{B}, \mathbf{C})$ in rats suspended for 14 days. Clomipramine treatment of the suspended rats partly prevented muscle atrophy. The images of transverse sections of muscle fibers were obtained by staining with anti-caveolin-3 antibodies. Control - soleus muscle of the intact rat; HS 14d - unloaded muscle of the hindlimb suspended rat, HS 14d + clom - muscles of the rat suspended and treated with clomipramine.

\section{Caspase-3/7 and caspase-6}

In our experiment, caspase-3/7 and caspase- 6 activities were measured according to the manufacturer's protocol. The method used for caspase-3 assaying allowed us to detect both caspase-3 and -7 activities due to their ability to cleave the same substrate (DEVD-pNA). We revealed that caspase-3/7 and caspase- 6 activity became higher than in the control animals only on the $4^{\text {th }}$ day of unloading (fig. 7). The activity of caspase-3/7 enhanced 2.5 -fold and that of caspase-6 increased 3.4-fold in comparison with the control values $(p<0.000)$. However, after the 14-day HS the activity of both caspases restored to the basal levels. It should be noted that, similarly to the changes in aSMase, nSMase, ceramide and Nox2 abundabce in DRM (lipid 
rafts), the highest caspase-3/7 and caspase- 6 activities were detected on the $4^{\text {th }}$ day of HS (fig. 1 , 2, 3). The same dynamics demonstrated the changes in the level of TBA-active products (fig. 5)
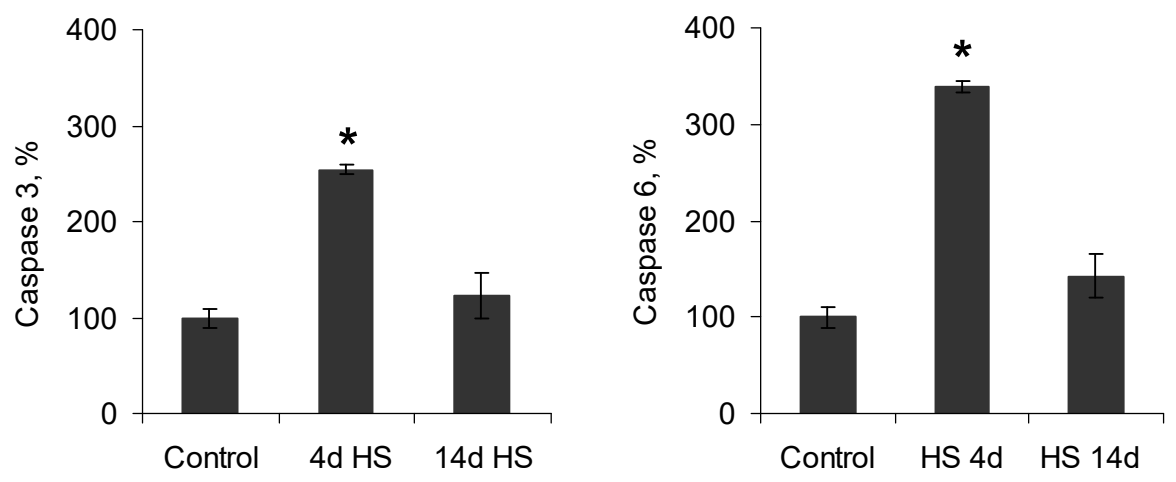

Figure 7. Caspase- $3 / 7$ and caspase- 6 activities enhanced on the $4^{\text {th }}$ day of HS; ${ }^{*}-p<0.05$ in comparison with the control values.

\section{Bax, Bcl2 and Bax/Bcl2 ratio}

To estimate the pro-apoptotic events in the atrophic soleus muscle, we also detected Bax and Bcl2 proteins expression and calculated Bcl-2/ Bax ratio. The amount of Bax was 33\% increased in the soleus muscles of rats suspended for 14 days. At the same time, Bcl 2 abundance was $42 \%$ decreased, therefore, $\mathrm{Bax} / \mathrm{Bcl} 2$ ratio enhanced more than 4-fold (fig. 8). Interestingly, aSMase inhibition with clomipramine abolished Bax up-regulation, whereas did not affect Bcl-2 downregulation.
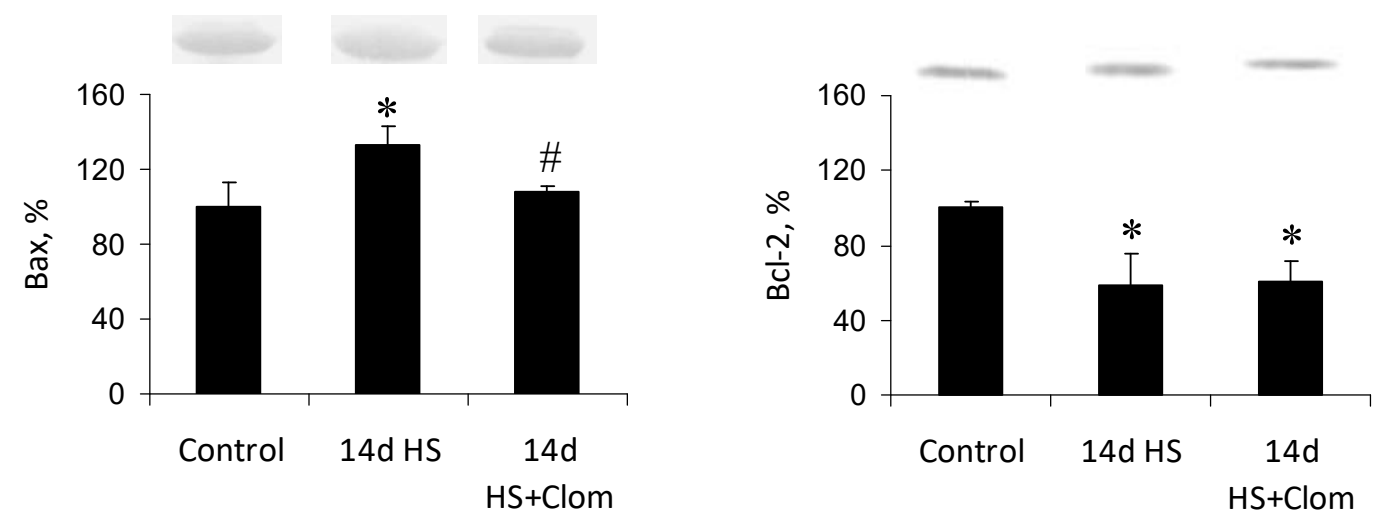

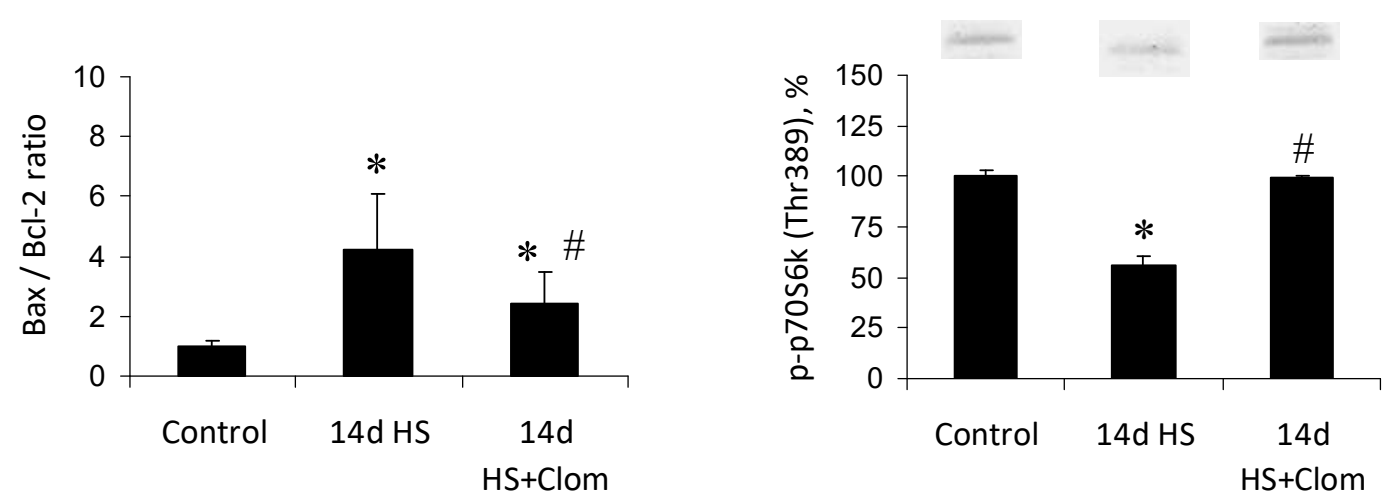

GAPDH

Control 14d HS HS+Clom

Figure 8. Bax is up-regulated, Bcl-2 and p-p70S6k (Thr389) are down-regulated in the soleus muscle disused for 14 days. Clomipramine treatment abolishes the enhancement of Bax and prevents the decrease in p70S6k (Thr389). * - p<0.05 in comparison with the control value, \# $\mathrm{p}<0.05$ in comparison with HS.

\section{mTORC1/p70S6k signaling}

Disuse muscle atrophy is a result of dysbalance between protein synthesis and protein degradation. Therefore, we assessed the changes in the downstream molecule of anabolic mTORC1 signaling pathway (p70S6k) occurred in soleus muscle during unloading. We demonstrated that this pathway was considerably down-regulated in the soleus muscle of 14-day suspended rats: phosphorylation of p70S6k by the activation site (Thr389) was $45 \%$ decreased. Clomipramine treatment prevented the decrease in p70S6k (Thr389) phosphorylation (fig. 8).

\section{Discussion}

In our previous studies, we have shown for the first time that ceramide accumulates in the soleus muscle of mice subjected to hindlimb suspension during 4 or 30 days [46]. We established that ceramide accumulation was not apparently associated with activation of the first step process in the de novo pathway of ceramide biosynthesis but with enhanced sphingomyelinase hydrolysis. The potential ability of ceramide to be involved in the development of disuse muscle atrophy was studied by [47]. The authors showed that serine palmitoyltranspherase 2 is up-regulated in rat soleus muscle unloaded for 7 days. They used myriocin, an inhibitor of de novo ceramide biosynthesis, to prevent ceramide accumulation and, therefore, muscle atrophy. However, despite 
the decrease in the soleus muscle ceramide level in tail-suspended animals treated with myriocin, this drug did not prevent muscle atrophy.

In the present work, we have shown that clomipramine, the inhibitor of aSMase pathway of ceramide formation, can diminish a degree of muscle disuse atrophy. This finding evidences that atrophic effect of ceramide may depend on the myocellular compartment in which it is generated and the pathway involved. In this context, it is worth mentioning that the decrease of insulin sensitivity caused by ceramide in insulin-resistant individuals is mainly due to its effect on the processes localized to the sarcolemma [48]. Tan-Chen and co-authors [49] notice that this can explain the data obtained earlier by some authors about the absence of an association of muscle insulin resistance with up-regulation of ceramide synthases which are known to be involved in the de novo and salvage pathways of ceramide biosynthesis.

Analogously, we have supposed that the de novo synthesis is not the main source of ceramide accumulation in disused muscle because we did not find its up-regulation in soleus muscle of mice that underwent HS (Bryndina, 2014). In addition, we have shown that the inhibitor of acid sphingomyelinase clomipramine prevents or attenuates some effects of muscle disuse, like following: ceramide accumulation [46], lipid raft disruption [19], formation of ceramideenriched membrane domains [41], as well as the disturbance of membrane lipid asymmetry and formation of ceramide-containing vesicles [6]. Thus, we believe that aSMase mechanism is predominant in ceramide generation during disuse and it may be involved in the development of disuse muscle atrophy. Our present work confirms this suggestion. Indeed, application of the inhibitor of aSMase clomipramine effectively attenuates aSMase/ceramide enhancement in 14day unloaded soleus muscle and, at the same time, mitigates its atrophy. This effect has been obtained for the first time.

Taking into account the ability of aSMase to be activated by TNFa [50] we decided to test the hypothesis that aSMase activation due to unloading is TNFR1-dependent. Earlier we have not found TNFa changes in unloaded for 12 hours rat soleus muscle [6], and our observation is in agreement with the data of [4]. Interestingly, despite this, we detected the increased TNFR1 expression in the detergent insoluble membrane fraction (lipid rafts) of disused muscle. This finding indicates that up-regulation of TNFR1 precedes cytokine accumulation and, therefore, may enhance muscle susceptibility to its action in the early period of disuse.

It is known that ceramide-enriched domains forming in cell membranes due to activation of the aSMase/ceramide pathway are able to serve as functional platforms for the clustering of death receptors like FasR and TNFR [51]. In accordance with this hypothesis we supposed that a decline in the abundance of ceramide-enriched domains may decrease TNFR1 availability in DRM. However, the absence of TNFR1 response to clomipramine treatment in hindlimb 
suspended rats probably indicates that this mechanism is not substantial in unloaded muscle. Apparently, high TNFR1 expression exerts downstream effect upon aSMase/ceramide, but not vice versa [6].

Studying TNFR1 expression in the present work, we have obtained the results similar to our earlier findings, but the increase in TNFR1 abundance in lipid rafts after 4 or 14 days of HS was more considerable than in 12-hour exposure. Importantly, TNFa amount in rat soleus muscle is also increased in this period of unloading [4]. Regression analysis demonstrated a strong positive correlation between TNFR1 and aSMase levels confirming that aSMase/ceramide activation may be associated with the enhanced cytokine effect. The parameter of the linear correlation between TNFR1 and aSMase or nSMase were the following: $F=72.907, p=0.000$ for aSMase and $\mathrm{F}=6.031, \mathrm{p}=0.021$ for $\mathrm{nSMase}$.

An increase in ceramide abundance in the membrane regions of unloaded soleus muscle obtained in our immunofluorescence and biochemical studies as well as the efficacy of clomipramine treatment in prevention of this effect confirms the involvement of aSMasedependent pathway in ceramide generation.

It is known that multiple effects of ceramide in different cells occur through diverse targets such as SAPK, PPA2, PKC $\zeta$ activation and other mechanisms [52]. A number of authors think that disuse-induced muscle atrophy is associated with oxidative stress [53, 54, 55]. It has been established that sphingomyelinase stimulates oxidant signaling in skeletal muscles through NADPH oxidase activation, thereby promoting muscle contractile dysfunction, weakness and fatigue $[27,56]$.

One aspect of ceramide and pro-oxidant capacity relationships in skeletal muscles is that heightened aSMase activity leads to the formation of ceramide enriched membrane domains which are able to facilitate recruitment, assembling and activation of NADPH-oxidase complex [57]; therefore such domains can function as redox signaling platforms. This effect has been described in different cells $[58,59,60]$. Previously we observed the formation of ceramideenriched domains in the plasma membranes of disused rat soleus muscle [41]. It is possible that, during muscle unloading, this mechanism can promote the recruitment and activation of NADPH-oxidase complex. The results of our present experiments are in agreement with this conclusion. Nox 2 is up-regulated in the detergent insoluble fraction of soleus muscle, and clomipramine treatment attenuates this effect. Interestingly, regression analysis demonstrated a strong positive correlation between both SMases and Nox2 DRM abundance. The parameter of the linear correlation between aSMase or nSMase and Nox2 were the following: $F=46.99$, $\mathrm{p}=0.000$ for aSMase and $\mathrm{F}=22.931, \mathrm{p}=0.000$ for $\mathrm{nSMase}$. It supported our opinion about the dependence of Nox 2 changes on the SMases membrane amounts. 
Another important aspect of pro-oxidant action of ceramide is that it exerts a direct effect on the generation of reactive oxygen species in mitochondria [61]. Activation of NADPHoxidase 4 (Nox4) is one of the key pathways of ROS generation in these subcellular structures. Biological role of Nox4 in skeletal muscle is not fully understood. It is known that the enzyme is localized predominantly in the plasma membrane, sarcoplasmic reticulum, T-tubules and mitochondria inner membrane $[62,43,63,64]$. Nox4 is considered to be a hydrogen peroxidegenerating oxygen sensor $[63,65,66]$. It has been established that Nox4-dependent ROS production contributes to the muscle $\mathrm{Ca}^{2+}$ homeostasis inducing $\mathrm{RyR} 1 \mathrm{Ca}^{2+}$ leak [67]. Previously, the increased expression of Nox4 was found in m. quadriceps femoris of 10-day tailsuspended mice [68].

In our present work we have demonstrated that 14-day HS leads to an enhancement in soleus muscle Nox4 expression with considerable rearrangement in its distribution across muscle fibers; clomipramine treatment considerably attenuates this effect. These data was obtained for the first time. As would be expected, in addition to Nox 2 and Nox4 changes we observed a significant growth of TBA-active products in soleus muscle homogenates on the $4^{\text {th }}$ day of unloading. SOD1 and GPX activity remained unchanged, whereas catalase activity declined on the $14^{\text {th }}$ day of HS.

The role of aSMase/ceramide in Nox 2 and Nox 4 enhancement and rearrangement is proved by the efficacy of clomipramine treatment in prevention of their up-regulation in the soleus muscle of HS groups of animals. Note oxidative mechanisms may enhance myofibrillar protein degradation via calpain and caspase-3 [69]. Moreover, TNF-a-induced mitochondrial production of reactive oxygen species (ROS) is important mechanism in rapid activation of the ubiquitin pathway and proteasomal degradation of I-kBa, leading to NFkB-dependent expression of genes involved in the induction of muscle proteolysis [70, 71, 72].

$\mathrm{TNFa}$ is known to induce an extrinsic caspase-dependent mechanism of apoptosis. Apoptosis is one of the possible ways that can contribute to the development of disuse muscle atrophy caused by denervation [73], immobilization [74, 75], and hindlimb unloading [47, 76, 77]. It has been observed in many cell types that TNFa causes a rapid and significant accumulation of ceramide and sphingosine during the first hour of treatment in many cell types [52]. Ceramide, in its turn, is considered to be a proapoptotic factor known to induce caspase-dependent and caspaseindependent apoptosis [78, 79, 80]. It has been found [47] that an increase in cleaved caspase-3 and $\mathrm{Bax} / \mathrm{Bcl}-2$ ratio in the soleus muscle of rats subjected to 7-day hindlimb unloading coexists with the heightened ceramide level. 
Pro-apoptotic events may depend on increased pro-oxidant Nox 2 and Nox4 activity [81], and this phenomenon has been described as well in striated muscles [44]. Interestingly, [82] have found that the enhanced expression of pro-caspase-3 protein in human skeletal muscles disused after spinal cord injury may be associated with the Nox 2 and Nox 4 up-regulation. These data conforms to our findings of simultaneous increase in Nox2/ Nox4 abundance and caspase-3 activity in the unloaded soleus muscle. It is known that a group of effector/ executional caspases includes caspase-3,-6 and -7. In our experiment, caspase-3 activity increased more than 2.5-fold by the $4^{\text {th }}$ day of HS, but it did not differ from the control level after the $14^{\text {th }}$ day of disuse. Due to the nature of the substrate (DEVD-pNA), the method used in our work allowed to estimate the activity of both caspase 3 and 7 (noted by the manufacturer). Thus, we can conclude that executioner caspases were activated by the $4^{\text {th }}$ day of disuse. Interestingly, it has been found [76] that the mean numbers of total and muscle apoptotic (TDT-positive) nuclei were significantly increased as early as after 3 days of HS, and this phenomenon preceded significant muscle atrophy appearing after 7 days of unloading. This finding agrees with the data of [83] shown that activation of caspase- 3 is an early event in the development of the disuse muscle atrophy, which can be revealed on the $5^{\text {th }}$ day of unloading. Importantly, caspase- 3 activation is the initial and significant step triggering accelerated muscle proteolysis in catabolic conditions [84]. Our results also correspond to the data of [85] who have shown the absence of significant changes in caspase-3 activity in two-week leg immobilization in human. It should be noted that the other authors described caspase-3 activation after 14-day HS [86, 5, 87].

Another marker of apoptosis in our study was pro-apoptotic Bax / anti-apoptotic Bcl-2 proteins [88]. We demonstrated that Bax abundance was increased, whereas Bcl-2 content was decreased indicating the prevalence of pro-apoptotic events in the 14-day disused soleus muscle. Clomipramine treatment of the suspended rats attenuated the enhancement of Bax protein, whereas did not prevent Bcl-2 down-regulation. According to the data of [77], pro-apoptotic Bax and anti-apoptotic Bcl-2 mRNA contents were up-regulated in 14-day unloaded medial gastrocnemius of young, adult and aged Fischer $344 *$ Brown Norway rats. In the experiments of the other authors [47], the increase in Bax/Bcl-2 ratio was obtained in Wistar rats on the $7^{\text {th }}$ day of HS. The enhanced Bax abundance (14-day HS) was also found by [87]. Our results suggest that anti-apoptotic effect of clomipramine in the unloaded muscle may be realized through inhibition of Bax up-regulation.

It is generally accepted that muscle atrophy is associated with a dysbalance between protein synthesis and degradation [89]. The decrease in protein synthesis in the period of 3-5 days of HS ranged from $21 \%$ to $60 \%$ [90, 91, 92, 93, 94]. The main mechanism in regulation of protein synthesis in skeletal muscles is mTORC1 dependent activation of ribosomal protein kinase p70 
(p70S6k) through phosphorylation at Thr389. In our experiment the levels of p-p70S6k (Thr389) declined on the $14^{\text {th }}$ day of HS. Our results are in agreement with the finding of [95] who obtained the similar results after 3.5-day unloading.

Ceramide is known to exert down-regulation of protein synthesis due to its property to inhibit mTORC1 signaling through atypical PKC $\zeta$ and phosphatase PP2A - associated Akt dephosphorylation, endolysosomal catepsin D and NF-kappa B activation [96, 97]. Additionally to dephosphorylation of translation regulators lying downstream of mTOR, ceramide is able to deplete the plasma membrane abundance of the amino acids transporter SNAT2, thereby, diminishing intramyocellular amino acid availability [97]. In our experiment, we have shown that clomipramine attenuates HS-induced decrease in p-p70S6k(Thr389) protein amount in disused soleus muscle, indicating the involvement of aSMase/ ceramide in the regulation of this pathway during unloading.

\title{
Conclusions
}

The obtained results indicate the involvement of aSMase/ ceramide in the development of disuse muscle atrophy. This effect may be triggered by TNFR1 and realizes through enhanced prooxidant NADPH oxidase activity, pro-apoptotic and pro-catabolic/ anti-anabolic signaling. The inhibitor of aSMase clomipramine significantly attenuates the signs of atrophy in disused soleus muscle diminishing the loss of muscle mass, as well as the decline in CSA and diameter of muscle fibers. The main mechanisms of anti-atrophic effect of clomipramine is suppression of Nox 2 and Nox 4 pro-oxidant activity and inhibition of ceramide-induced anti-anabolic signaling.

\begin{abstract}
Abbreviations
TNFR1 - TNFa receptor 1, aSMase and nSMase - acid and neutral sphingomyelinase, DRM detergent-resistant membranes, BSA - bovine serum albumin, FITC - fluorescein 5isothiocyanat, SOD - superoxide dismutase, GPx - glutathione peroxidase, SAPK - stress activated protein kinase, PPA2 - protein phosphatase $\mathrm{A} 2, \mathrm{PKC} \zeta$ - atypical protein kinase $\mathrm{C}$ zeta, CSA - cross-sectional area, mTORC1 - mammalian (mechanistic) target of rapamycin, p70S6k - ribosomal protein S6 kinase, Nox2, Nox4 - NADPH oxidase isoforms 2 and 4
\end{abstract}

\section{Acknowledgements}

Not applicable

\section{Authors' contributions}

I.B. designed experiments, analyzed and interpreted the data, and wrote the manuscript. N.O., V.P., M.Sh. performed experiments and analyzed the data, A.S. performed experiments. All authors read and approved the final manuscript.

\section{Funding}


This study was supported by Russian Science Foundation (grant \#16-15-10220)

\section{Availability of data and materials}

Most data that was generated for this study is included in the manuscript. The corresponding author can be contacted if additional data is required.

\section{Ethics approval and consent to participate}

All experiments on rats were carried out according to the experimental protocol met the requirements of the EU Directive 2010/63/EU and was approved by the Bioethics Committees of Izhevsk State Medical Academy (protocol \#502/1 from 6.09.2016.

\section{Consent for publication}

Not applicable

\section{Competing interests}

The authors declare that they have no competing financial interests.

\section{References}

1. Reid MB, Li Yi-Ping. Reid MB, Li YP. Tumor necrosis factor-alpha and muscle wasting: a cellular perspective. Respir Res. 2001;2(5):269-72.

2. Zhou J, Liu B, Liang C, Li Y, Song YH. Cytokine Signaling in Skeletal Muscle Wasting. Trends Endocrinol Metab. 2016;27(5):335-347.

3. Hunter RB, Stevenson E, Koncarevic A, Mitchell-Felton H, Essig DA, Kandarian SC. Activation of an alternative NF-kappaB pathway in skeletal muscle during disuse atrophy. FASEB J. 2002;16(6):529-38.

4. Hirose T, Nakazato K, Song H, Ishii N. TGF-beta1 and TNF-alpha are involved in the transcription of type I collagen alpha2 gene in soleus muscle atrophied by mechanical unloading. J Appl Physiol (1985). 2008;104(1):170-7.

5. Andrianjafiniony T, Dupré-Aucouturier S, Letexier D, Couchoux H, Desplanches D. Oxidative stress, apoptosis, and proteolysis in skeletal muscle repair after unloading. Am J Physiol Cell Physiol. 2010;299(2):C307-15.

6. Petrov AM, Shalagina MN, Protopopov VA, Sergeev VG, Ovechkin SV, Ovchinina NG, Sekunov AV, Zefirov AL, Zakirjanova GF, Bryndina IG. Changes in membrane ceramide pools in rat soleus muscle in response to short-term disuse. Int $\mathrm{J}$ Mol Sci. 2019;20(19):4860. doi:10.3390/ijms20194860.

7. Petry ÉR, Dresch DF, Carvalho C, Medeiros PC, Rosa TG, de Oliveira CM, Martins LAM, Schemitt E, Bona S, Guma FCR, Marroni NP, Wannmacher CMD. Oral glutamine supplementation attenuates inflammation and oxidative stress-mediated skeletal muscle protein content degradation in immobilized rats: Role of $70 \mathrm{kDa}$ heat shock protein. Free Radic Biol Med. 2019;145:87-102.

8. Bunn JA, Buford TW, Serra MC, Kreider RB, Willoughby DS. Protein and amino acid supplementation does not alter proteolytic gene expression following immobilization. J Nutr Metab. 2011;2011:539690. doi: 10.1155/2011/539690.

9. Libert C. Cytokine anniversary: TNF trailblazers five centuries apart. Nature. 2015;9;523(7559):158. doi: 10.1038/523158e.

10. Pedersen BK. Muscles and their myokines. J Exp Biol. 2011; 214(Pt 2):337-46.

11. Steffen BT, Lees SJ, Booth FW. Anti-TNF treatment reduces rat skeletal muscle wasting in monocrotaline-induced cardiac cachexia. J Appl Physiol (1985). 2008;105(6):1950-8. 
12. Sasi SP, Rahimi L, Yan X, Silver M, Qin G, Losordo DW, Kishore R, Goukassian DA. Genetic deletion of TNFR2 augments inflammatory response and blunts satellite-cellmediated recovery response in a hind limb ischemia model. FASEB J. 2015;29(4):120819.

13. Peraldi P, Hotamisligil GS, Buurman WA, White MF, Spiegelman BM. Tumor necrosis factor (TNF)-alpha inhibits insulin signaling through stimulation of the p55 TNF receptor and activation of sphingomyelinase. J Biol Chem. 1996;271(22):13018-22.

14. Alesenko AV, Solov'ev AS, Terent'ev AA, Khrenov AV. [The role of sphingomyelin cycle products in development of apoptosis mediated by Fas receptors and tumor necrosis factor alpha]. Izv Akad Nauk Ser Biol. 1998;2:157-66. Russian.

15. Schwandner R, Wiegmann K, Bernardo K, Kreder D, Kronke M. TNF receptor death domain-associated proteins TRADD and FADD signal activation of acid sphingomyelinase. J Biol Chem. 1998;273(10):5916-22.

16. Osawa Y, Uchinami H, Bielawski J, Schwabe RF, Hannun YA, Brenner DA. Roles for C16-ceramide and sphingosine 1-phosphate in regulating hepatocyte apoptosis in response to tumor necrosis factor-alpha. J Biol Chem. 2005;280(30):27879-87.

17. Moylan JS, Smith JD, Wolf Horrell EM, McLean JB, Deevska GM, Bonnell MR, Nikolova-Karakashian MN, Reid MB. Neutral sphingomyelinase-3 mediates TNFstimulated oxidant activity in skeletal muscle. Redox Biol. 2014;2:910-20.

18. Supinski GS, Alimov AP, Wang L, Song XH, Callahan LA. Neutral sphingomyelinase 2 is required for cytokine-induced skeletal muscle calpain activation. Am J Physiol Lung Cell Mol Physiol. 2015;309(6):L614-24.

19. Bryndina IG, Shalagina MN, Sekunov AV, Zefirov AL, Petrov AM. Clomipramine counteracts lipid raft disturbance due to short-term muscle disuse. Neurosci Lett. 2018;664:1-6.

20. Tayek JA. Effects of tumor necrosis factor alpha on skeletal muscle amino acid metabolism studied in-vivo. J Am Coll Nutr. 1996;15(2):164-8.

21. Meadows KA, Holly JM, Stewart CE. Tumor necrosis factor-alpha-induced apoptosis is associated with suppression of insulin-like growth factor binding protein-5 secretion in differentiating murine skeletal myoblasts. J Cell Physiol. 2000;183(3):330-7.

22. Carbó N, Busquets S, van Royen M, Alvarez B, López-Soriano FJ, Argilés JM. TNFalpha is involved in activating DNA fragmentation in skeletal muscle. Br J Cancer. 2002;86(6):1012-6.

23. Lang CH, Frost RA, Nairn AC, MacLean DA, Vary TC. TNF-alpha impairs heart and skeletal muscle protein synthesis by altering translation initiation. Am J Physiol Endocrinol Metab. 2002;282(2):E336-47.

24. Adams V, Mangner N, Gasch A, Krohne C, Gielen S, Hirner S, Thierse HJ, Witt CC, Linke A, Schuler G, Labeit S. Induction of MuRF1 is essential for TNF-alpha-induced loss of muscle function in mice. J Mol Biol. 2008;384(1):48-59. doi: 10.1016/j.jmb.2008.08.087.

25. Ogura Y, Mishra V, Hindi SM, Kuang S, Kumar A. Proinflammatory cytokine tumor necrosis factor (TNF)-like weak inducer of apoptosis (TWEAK) suppresses satellite cell self-renewal through inversely modulating Notch and NF- $\kappa \mathrm{B}$ signaling pathways. J Biol Chem. 2013;288(49):35159-69. doi: 10.1074/jbc.M113.517300.

26. Baldwin KM, Haddad F, Pandorf CE, Roy RR, Edgerton VR. Alterations in muscle mass and contractile phenotype in response to unloading models: role of transcriptional/pretranslational mechanisms. Front Physiol. 2013;4:284.

27. Loehr JA, Abo-Zahrah R, Pal R, Rodney GG. Sphingomyelinase promotes oxidant production and skeletal muscle contractile dysfunction through activation of NADPH oxidase. Front Physiol. 2015;5:530.

28. Bollinger CR, Teichgräber V, Gulbins E. Ceramide-enriched membrane domains. Biochim Biophys Acta. 2005;1746(3):284-94. 
29. Yi F, Jin S, Li PL. Lipid raft-redox signaling platforms in plasma membrane. Methods Mol Biol. 2009;580:93-107.

30. Powers SK, Kavazis AN, DeRuisseau KC. Mechanisms of disuse muscle atrophy: role of oxidative stress. Am J Physiol Regul Integr Comp Physiol. 2005;288(2):R337-44.

31. Pellegrino MA, Desaphy JF, Brocca L, Pierno S, Camerino DC, Bottinelli R. Redox homeostasis, oxidative stress and disuse muscle atrophy. J Physiol. 2011;589(Pt 9):214760.

32. Il'in EA, Novikov VE. [Stand for modelling the physiological effects of weightlessness in laboratory experiments with rats]. Kosm Biol Aviakosm Med. 1980;14:79-80. Russian.

33. Morey-Holton ER, Globus RK. Hindlimb unloading rodent model: technical aspects. J Appl Physiol (1985). 2002;92:1367-77.

34. Radeva G, Sharom FJ. Isolation and characterization of lipid rafts with different properties from RBL-2H3 (rat basophilic leukaemia) cells. Biochem J. 2004;380:219-30.

35. Folch J, Lees M, Sloane-Stanley GH. A simple method for the isolation and purification of total lipides from animal tissues. J Biol Chem. 1957;226:497-509.

36. Higgins J.A. Separation and analysis of membrane lipid components. In: Findlay J.B.C., Evans W.H., editors. Biological Membranes: A Practical Approach. Washington: IRL Press; 1987. pp.103-137.

37. Laemmli UK. Cleavage of structural proteins during the assembly of the head of bacteriophage T4. Nature. 1970;15;227:680-5.

38. Boath A, Graf C, Lidome E, Ullrich T, Nussbaumer P, Bornancin F. Regulation and traffic of ceramide 1-phosphate produced by ceramide kinase: comparative analysis to glucosylceramide and sphingomyelin. J Biol Chem. 2008;283:8517-26.

39. Janero DR. Malondialdehyde and thiobarbituric acid-reactivity as diagnostic indices of lipid peroxidation and peroxidative tissue injury. Free Radic Biol Med. 1990;9:515-40.

40. Fedorova M, Kuleva N, Hoffmann R. Reversible and irreversible modifications of skeletal muscle proteins in a rat model of acute oxidative stress. Biochim Biophys Acta. 2009;1792:1185-93.

41. Bryndina IG, Protopopov VA, Sergeev VG, Shalagina MN, Ovechkin SV and Yakovlev AA. Ceramide enriched membrane domains in rat skeletal muscle exposed to short-term hypogravitational unloading. Front. Physiol. Conference Abstract: 39th ISGP Meeting \& ESA Life Sciences Meeting. 2019. doi: 10.3389/conf.fphys.2018.26.00028.

42. Ferreira LF, Laitano O. Regulation of NADPH oxidases in skeletal muscle. Free Radic Biol Med. 2016;98:18-28.

43. Block K, Gorin Y, Abboud HE. Subcellular localization of Nox4 and regulation in diabetes. Proc Natl Acad Sci U S A. 2009;106(34):14385-90.

44. Ago T, Kuroda J, Pain J, Fu C, Li H, Sadoshima J. Upregulation of Nox4 by hypertrophic stimuli promotes apoptosis and mitochondrial dysfunction in cardiac myocytes. Circ Res. 2010;106(7):1253-64.

45. Sakellariou GK, Vasilaki A, Palomero J, Kayani A, Zibrik L, McArdle A, Jackson MJ. Studies of mitochondrial and nonmitochondrial sources implicate nicotinamide adenine dinucleotide phosphate oxidase(s) in the increased skeletal muscle superoxide generation that occurs during contractile activity. Antioxid Redox Signal. 2013;18(6):603-21.

46. Bryndina IG, Shalagina MN, Ovechkin SV, Ovchinina NG. [Sphingolipids in skeletal muscles of C57B1/6 mice after short-term simulated microgravity]. Ross Fiziol Zh Im I M Sechenova. 2014;100(11):1280-6. Russian.

47. Salaun E, Lefeuvre-Orfila L, Cavey T, Martin B, Turlin B, Ropert M, Loreal O, Derbré F. Myriocin prevents muscle ceramide accumulation but not muscle fiber atrophy during short-term mechanical unloading. J Appl Physiol (1985). 2016;120(2):178-87.

48. Chung JO, Koutsari C, Blachnio-Zabielska AU, Hames KC, Jensen MD. Intramyocellular ceramides: subcellular concentrations and fractional de novo synthesis in postabsorptive humans. Diabetes. 2017;66:2082-91. 
49. Tan-Chen S, Guitton J, Bourron O, Le Stunff H, Hajduch E. Sphingolipid Metabolism and Signaling in Skeletal Muscle: From Physiology to Physiopathology. Front Endocrinol (Lausanne). 2020;11:491. doi: 10.3389/fendo.2020.00491.

50. De Larichaudy J, Zufferli A, Serra F, Isidori AM, Naro F, Dessalle K, Desgeorges M, Piraud M, Cheillan D, Vidal H, Lefai E, Némoz G. TNF- $\alpha$ - and tumor-induced skeletal muscle atrophy involves sphingolipid metabolism. Skelet Muscle. 2012;2(1):2. doi: 10.1186/2044-5040-2-2.

51. Gulbins E, Grassmé H. Ceramide and cell death receptor clustering. Biochim Biophys Acta. 2002;1585(2-3):139-45.

52. Woodcock J. Sphingosine and ceramide signalling in apoptosis. IUBMB Life. 2006;58(8):462-6.

53. Lawler JM, Song W, Demaree SR Hindlimb unloading increases oxidative stress and disrupts antioxidant capacity in skeletal muscle. Free Radic Biol Med. 2003;35(1):9-16.

54. Powers SK, Kavazis AN, DeRuisseau KC. Mechanisms of disuse muscle atrophy: role of oxidative stress. Am J Physiol Regul Integr Comp Physiol. 2005;288(2):R337-44.

55. Pellegrino MA, Desaphy JF, Brocca L, Pierno S, Camerino DC, Bottinelli R. Redox homeostasis, oxidative stress and disuse muscle atrophy. J Physiol. 2011;589(Pt 9):214760.

56. Ferreira LF, Moylan JS, Gilliam LA, Smith JD, Nikolova-Karakashian M, Reid MB. Sphingomyelinase stimulates oxidant signaling to weaken skeletal muscle and promote fatigue. Am J Physiol Cell Physiol. 2010;299(3):C552-60.

57. Li PL, Zhang Y. Cross talk between ceramide and redox signaling: implications for endothelial dysfunction and renal disease. Handb Exp Pharmacol. 2013;216:171-97.

58. Zhang Y, Li X, Carpinteiro A, Gulbins E. Acid sphingomyelinase amplifies redox signaling in Pseudomonas aeruginosa-induced macrophage apoptosis. J Immunol. 2008;181(6):4247-54.

59. Jin S, Zhou F. Lipid raft redox signaling platforms in vascular dysfunction: features and mechanisms. Curr Atheroscler Rep. 2009;11(3):220-6.

60. Bost ER, Frye GS, Ahn B, Ferreira LF. Diaphragm dysfunction caused by sphingomyelinase requires the p47(phox) subunit of NADPH oxidase. Respir Physiol Neurobiol. 2015;205:47-52.

61. Garcia-Ruiz C, Colell A, Mari M, Morales A, and Fernandez-Checa JC. Direct effect of ceramide on the mitochondrial electron transport chain leads to generation of reactive oxygen species. Role of mitochondrial glutathione. J Biol Chem. 1997;272:11369-77.

62. Bedard K, Krause KH. The NOX family of ROS-generating NADPH oxidases: physiology and pathophysiology. Physiol Rev. 2007;87(1):245-313.

63. Sun QA, Hess DT, Nogueira L, Yong S, Bowles DE, Eu J, Laurita KR, Meissner G, Stamler JS. Oxygen-coupled redox regulation of the skeletal muscle ryanodine receptor$\mathrm{Ca} 2+$ release channel by NADPH oxidase 4 . Proc Natl Acad Sci U S A. 2011;108(38):16098-103.

64. Sakellariou GK, Jackson MJ, Vasilaki A. Redefining the major contributors to superoxide production in contracting skeletal muscle. The role of $\mathrm{NAD}(\mathrm{P}) \mathrm{H}$ oxidases. Free Radic Res. 2014;48(1):12-29.

65. Nisimoto Y, Diebold BA, Cosentino-Gomes D, Lambeth JD. Nox4: a hydrogen peroxidegenerating oxygen sensor. Biochemistry. 2014;53(31):5111-20.

66. Shanmugasundaram K, Nayak BK, Friedrichs WE, Kaushik D, Rodriguez R, Block K. NOX4 functions as a mitochondrial energetic sensor coupling cancer metabolic reprogramming to drug resistance. Nat Commun. 2017;8(1):997.

67. Cully TR, Rodney GG. Nox4 - RyR1 - Nox2: Regulators of micro-domain signaling in skeletal muscle. Redox Biol. 2020;36:101557. doi: 10.1016/j.redox.2020.101557. 
68. Murata M, Kosaka R, Kurihara K, Yamashita S, Tachibana H. Delphinidin prevents disuse muscle atrophy and reduces stress-related gene expression. Biosci Biotechnol Biochem. 2016;80(8):1636-40.

69. Smuder AJ, Kavazis AN, Hudson MB, Nelson WB, Powers SK. Oxidation enhances myofibrillar protein degradation via calpain and caspase-3. Free Radic Biol Med. 2010;49(7):1152-60.

70. Llovera M, García-Martínez C, Agell N, López-Soriano FJ, Argilés JM. TNF can directly induce the expression of ubiquitin-dependent proteolytic system in rat soleus muscles. Biochem Biophys Res Commun. 1997;230(2):238-41.

71. Li YP, Schwartz RJ, Waddell ID, Holloway BR, Reid MB. Skeletal muscle myocytes undergo protein loss and reactive oxygen-mediated NF-kappa B activation in response to tumor necrosis factor alpha. FASEB J. 1998;12(10):871-80.

72. Saini A, Al-Shanti N, Stewart CE. Waste management - cytokines, growth factors and cachexia. Cytokine Growth Factor Rev. 2006;17(6):475-86.

73. Plant PJ, Bain JR, Correa JE, Woo M, Batt J. Absence of caspase-3 protects against denervation-induced skeletal muscle atrophy. J Appl Physiol (1985). 2009;107(1):22434.

74. Talbert EE, Smuder AJ, Min K, Kwon OS, Powers SK. Calpain and caspase-3 play required roles in immobilization-induced limb muscle atrophy. J Appl Physiol (1985). 2013;114(10):1482-9.

75. Zhu S, Nagashima M, Khan MA, Yasuhara S, Kaneki M, Martyn JA. Lack of caspase-3 attenuates immobilization-induced muscle atrophy and loss of tension generation along with mitigation of apoptosis and inflammation. Muscle Nerve. 2013;47(5):711-21.

76. Allen DL, Linderman JK, Roy RR, Bigbee AJ, Grindeland RE, Mukku V, Edgerton VR. Apoptosis: a mechanism contributing to remodeling of skeletal muscle in response to hindlimb unweighting. Am J Physiol. 1997;273(2 Pt 1):C579-87.

77. Siu PM, Pistilli EE, Alway SE. Apoptotic responses to hindlimb suspension in gastrocnemius muscles from young adult and aged rats. Am J Physiol Regul Integr Comp Physiol. 2005;289(4):R1015-26.

78. Obeid LM, Hannun YA. Ceramide: a stress signal and mediator of growth suppression and apoptosis. J Cell Biochem. 1995;58(2):191-8.

79. Alessenko AV. The role of sphingomyelin cycle metabolites in transduction of signals of cell proliferation, differentiation and death. Membr Cell Biol. 2000;13(2):303-20.

80. Thon L, Heike Möhlig, Sabine Mathieu, Arne Lange, Elena Bulanova, Supandi WinotoMorbach, Stefan Schütze, Silvia Bulfone-Paus, Dieter Adam Ceramide mediates caspaseindependent programmed cell death. FASEB J. 2005;19(14):1945-56.

81. Basuroy S, Bhattacharya S, Leffler CW, Parfenova H. Nox4 NADPH oxidase mediates oxidative stress and apoptosis caused by TNF-alpha in cerebral vascular endothelial cells. Am J Physiol Cell Physiol. 2009;296:C422-32.

82. Savikj M, Kostovski E, Lundell LS, Iversen PO, Massart J, Widegren U. Altered oxidative stress and antioxidant defence in skeletal muscle during the first year following spinal cord injury. Physiol Rep. 2019;7(16):e14218. doi: 10.14814/phy2.14218.

83. Berthon P, Duguez S, Favier FB, Amirouche A, Feasson L, Vico L, Denis C, Freyssenet D. Regulation of ubiquitin-proteasome system, caspase enzyme activities, and extracellular proteinases in rat soleus muscle in response to unloading. Pflugers Arch. $2007 \mathrm{Jul} ; 454(4): 625-33$.

84. Du J, Wang X, Miereles C, Bailey JL, Debigare R, Zheng B, Price SR, Mitch WE. Activation of caspase-3 is an initial step triggering accelerated muscle proteolysis in catabolic conditions. J Clin Invest. 2004 Jan;113(1):115-23.

85. Glover EI, Yasuda N, Tarnopolsky MA, Abadi A, Phillips SM. Little change in markers of protein breakdown and oxidative stress in humans in immobilization-induced skeletal muscle atrophy. Appl Physiol Nutr Metab. 2010;35(2):125-33. 
86. Leeuwenburgh C, Gurley CM, Strotman BA, Dupont-Versteegden EE. Age-related differences in apoptosis with disuse atrophy in soleus muscle. Am J Physiol Regul Integr Comp Physiol. 2005;288(5):R1288-96.

87. Hao Y, Jackson JR, Wang Y, Edens N, Pereira SL, Alway SE. $\beta$-Hydroxy- $\beta$ methylbutyrate reduces myonuclear apoptosis during recovery from hind limb suspension-induced muscle fiber atrophy in aged rats. Am J Physiol Regul Integr Comp Physiol. 2011;301(3):R701-15.

88. Banjara S, Suraweera CD, Hinds MG, Kvansakul M. The Bcl-2 family: ancient origins, conserved structures, and divergent mechanisms. Biomolecules. 2020;10(1):128. doi: 10.3390/biom 10010128 .

89. Thomason DB, Booth FW. Atrophy of the soleus muscle by hindlimb unweighting. J Appl Physiol (1985). 1990;68(1):1-12.

90. Loughna P, Goldspink G, Goldspink DF. Effect of inactivity and passive stretch on protein turnover in phasic and postural rat muscles. J Appl Physiol (1985). 1986;61(1):173-9.

91. Munoz KA, Satarug S, Tischler ME. Time course of the response of myofibrillar and sarcoplasmic protein metabolism to unweighting of the soleus muscle. Metabolism. 1993;42(8):1006-12.

92. Fluckey JD, Dupont-Versteegden EE, Knox M, Gaddy D, Tesch PA, Peterson CA. Insulin facilitation of muscle protein synthesis following resistance exercise in hindlimbsuspended rats is independent of a rapamycin-sensitive pathway. Am J Physiol Endocrinol Metab. 2004;287(6):E1070-5.

93. Baehr LM, West DWD, Marshall AG, Marcotte GR, Baar K, Bodine SC. Muscle-specific and age-related changes in protein synthesis and protein degradation in response to hindlimb unloading in rats. J Appl Physiol (1985). 2017;122(5):1336-50.

94. Mirzoev T, Tyganov S, Vilchinskaya N, Lomonosova Y, Shenkman B. Key markers of mTORC1-dependent and mTORC1-independent signaling pathways regulating protein synthesis in rat soleus muscle during early stages of hindlimb unloading. Cell Physiol Biochem. 2016;39(3):1011-20.

95. Bajotto G, Sato Y, Kitaura Y, Shimomura Y. Effect of branched-chain amino acid supplementation during unloading on regulatory components of protein synthesis in atrophied soleus muscles. Eur J Appl Physiol. 2011;111(8):1815-28.

96. Chalfant CE, Kishikawa K, Mumby MC, Kamibayashi C, Bielawska A, Hannun YA. Long chain ceramides activate protein phosphatase-1 and protein phosphatase-2A. Activation is stereospecific and regulated by phosphatidic acid. J Biol Chem. 1999; 274(29):20313-7.

97. Hyde R, Hajduch E, Powell DJ, Taylor PM, Hundal HS. Ceramide down-regulates System A amino acid transport and protein synthesis in rat skeletal muscle cells. FASEB J. 2005;19(3):461-3. 

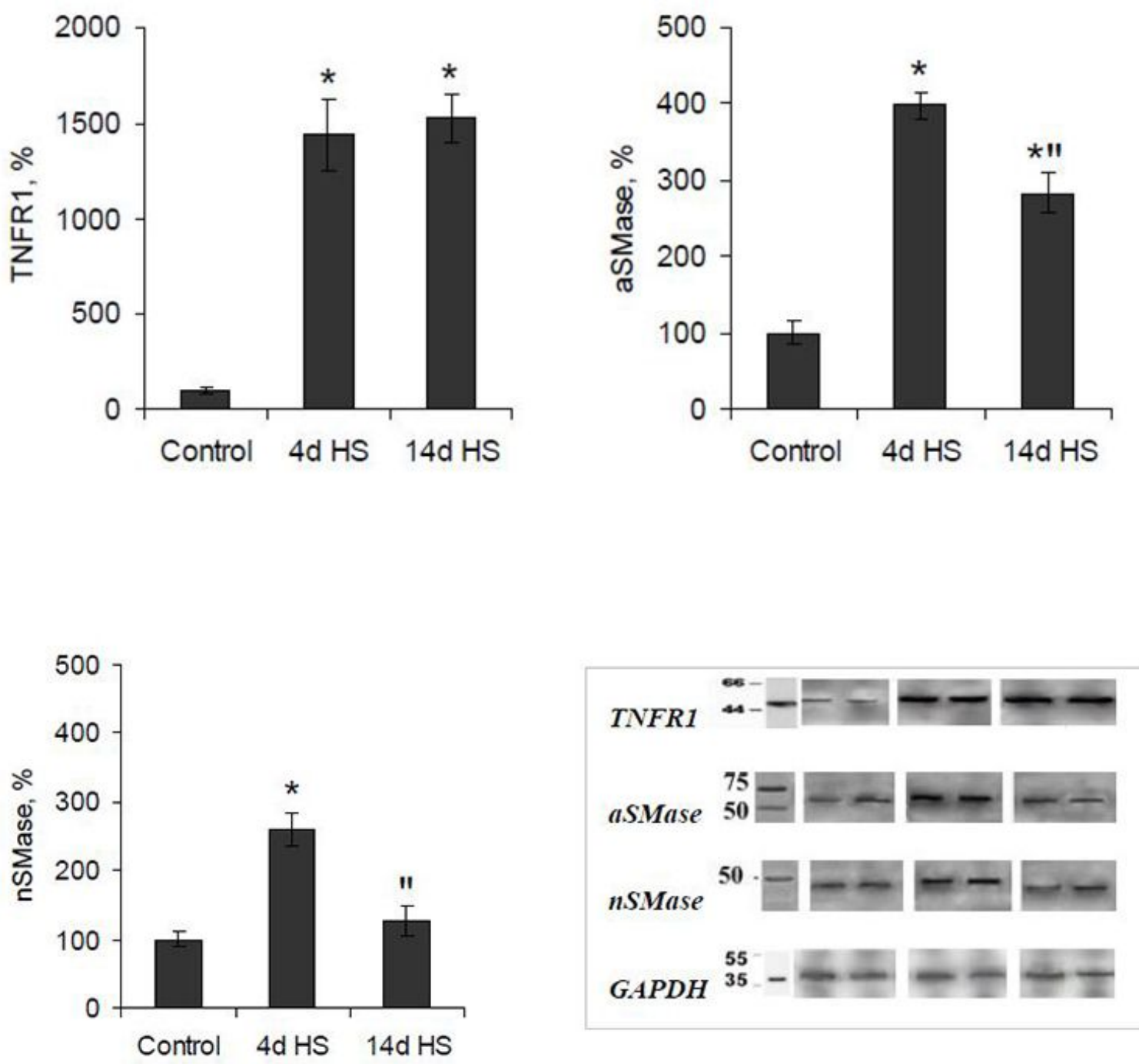

\section{Figure 1}

4-day and 14-day hindlimb suspension leads to the increase in abundance of TNFa receptor (TNFR1) with concomitant aSMase and nSMase elevation in detergent-resistant membrane fraction isolated from the rat soleus muscle homogenates (Western blot).TNFR1, aSMase increased at both 4th and 14th days 
of HS; nSMase increased only at the 4th day. * - $p<0.05$ - significant difference in comparison with control, " - significant difference between the 4th and 14th days of HS

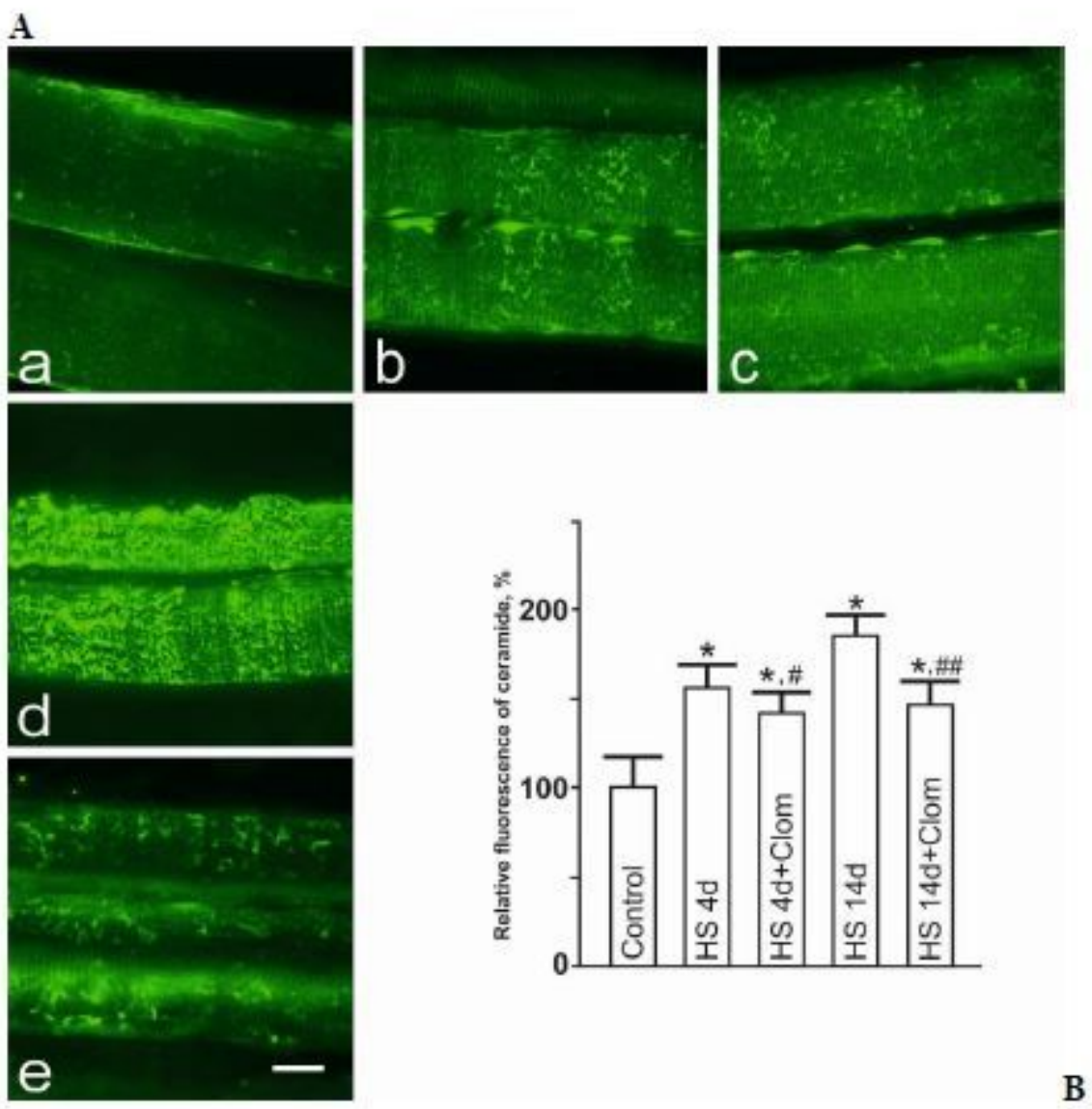

C

D
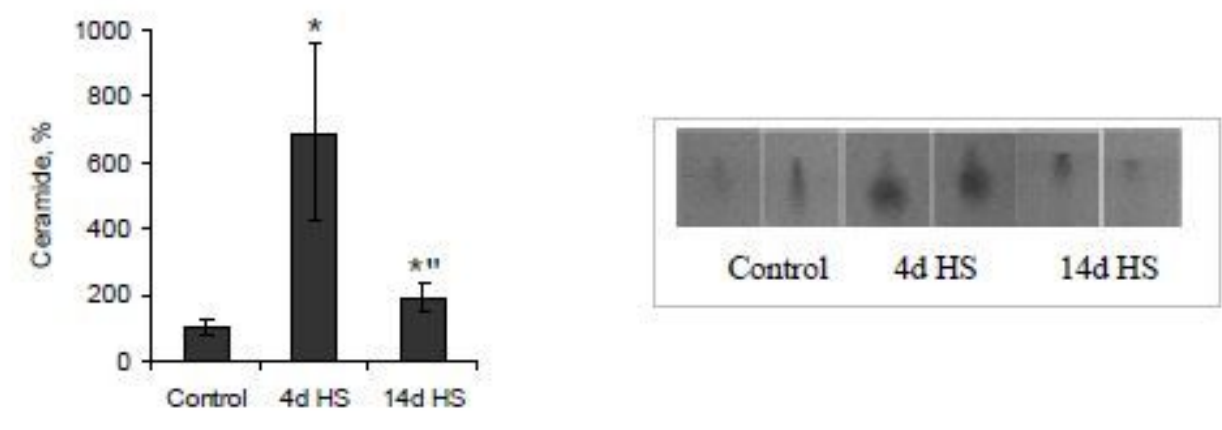

Figure 2

Ceramide is up-regulated in rat soleus muscle unloaded for 4 and 14 days. Immunofluorescence staining of ceramide on longitudinal sections of muscle fibers revealed the increase in ceramide abundance and formation of peculiar membrane structures looking like Control 4d HS 14d HS ceramide-enriched membrane domains: a - control, b - 4-day HS with vehicle, c - 4-day HS with clomipramine treatment; $d$ 14-day HS with vehicle, e - 14-day HS with clomipramine treatment; line length = $10 \mathrm{mcm}(\mathrm{A})$ Quantification of ceramide levels in unloaded for 4 and 14 days soleus muscle: the effect of 
clomipramine treatment. Clomipramine partly prevents ceramide up-regulation in the unloaded muscle (B) Ceramide in detergent-resistant membrane fraction (DRM) of soleus muscle homogenates; C ceramide in DRM (\%, HPTLC); D - ceramide spots in chromatograms, * $p<0.05$ - significant difference in comparison with control, \#p<0.05 - significant difference between the 14d HS and 14d HS+Clom, " p $<0.05$ - significant difference between the 4-day and 14-day HS

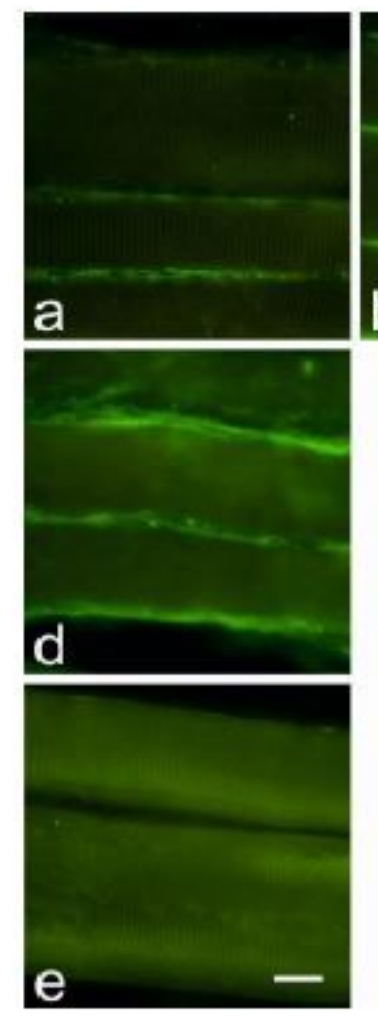

C

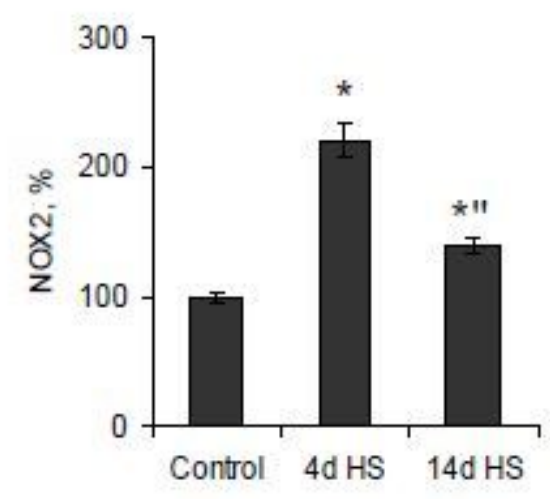

B

D

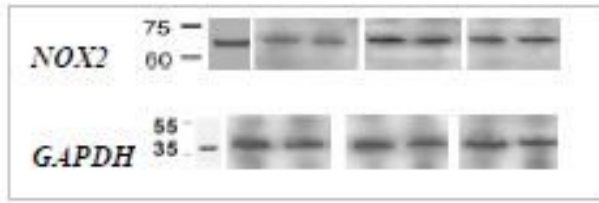

\section{Figure 3}

Up-regulation of NOX2 immunoreactivity in rat soleus muscle subjected to for 4- or 14-day unloading is partly prevented by clomipramine treatment: $\mathrm{a}$ - control, b - 4-day HS with vehicle, c - 4-day HS with clomipramine treatment; $d$ - 14-day HS with vehicle, e - 14-day HS with clomipramine treatment; line length $=10 \mathrm{mcm}(\mathrm{A})$. Quantitative analysis of NOX2 levels in suspended for 4 or 14 days soleus muscle in rats treated with clomipramine (Clom) or vehicle (B). NOX2 in detergent-resistant membrane fraction 
(DRM) detected by WB, in \% to the control value (C); * $p<0.05$ - significant difference in comparison with control, " $p<0.05$ - between the 4 th and 14 th days.
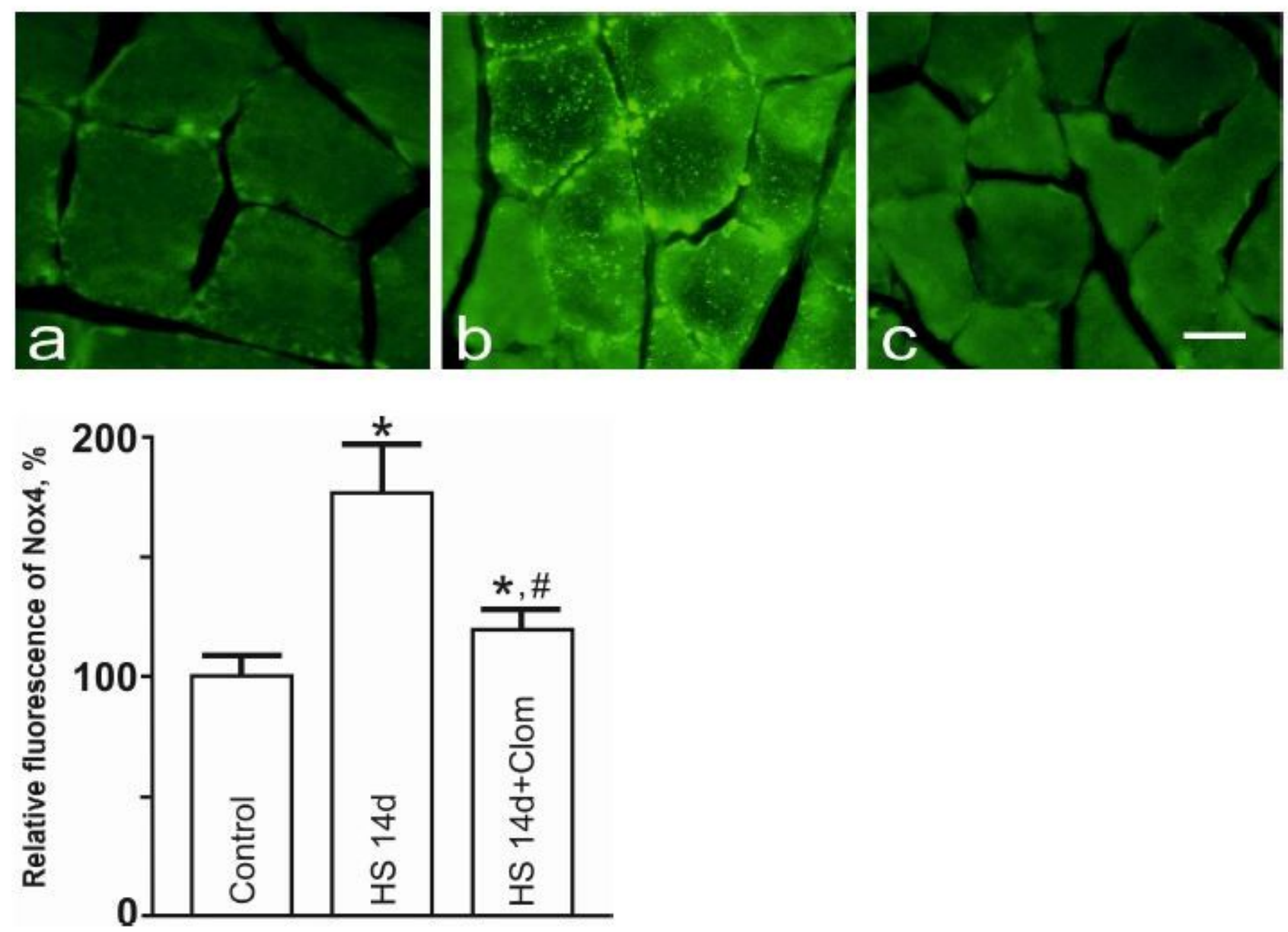

\section{Figure 4}

Hindlimb suspension (14 days) considerably alters the intensity and distribution of the Nox4 immune staining on the transverse sections of rat soleus muscle. Immunofluorescence is enhanced in the plasma membrane and intracellular compartments of muscle fibers. Clomipramine treatment decreases Nox4 abundance and rearranges its distribution. a - control, b - 14-day HS + vehicle, c - 14-day HS + clomipramine; * $p<0.05$, in comparison with control value, \# - $p<0.05$, in comparison with HS. 

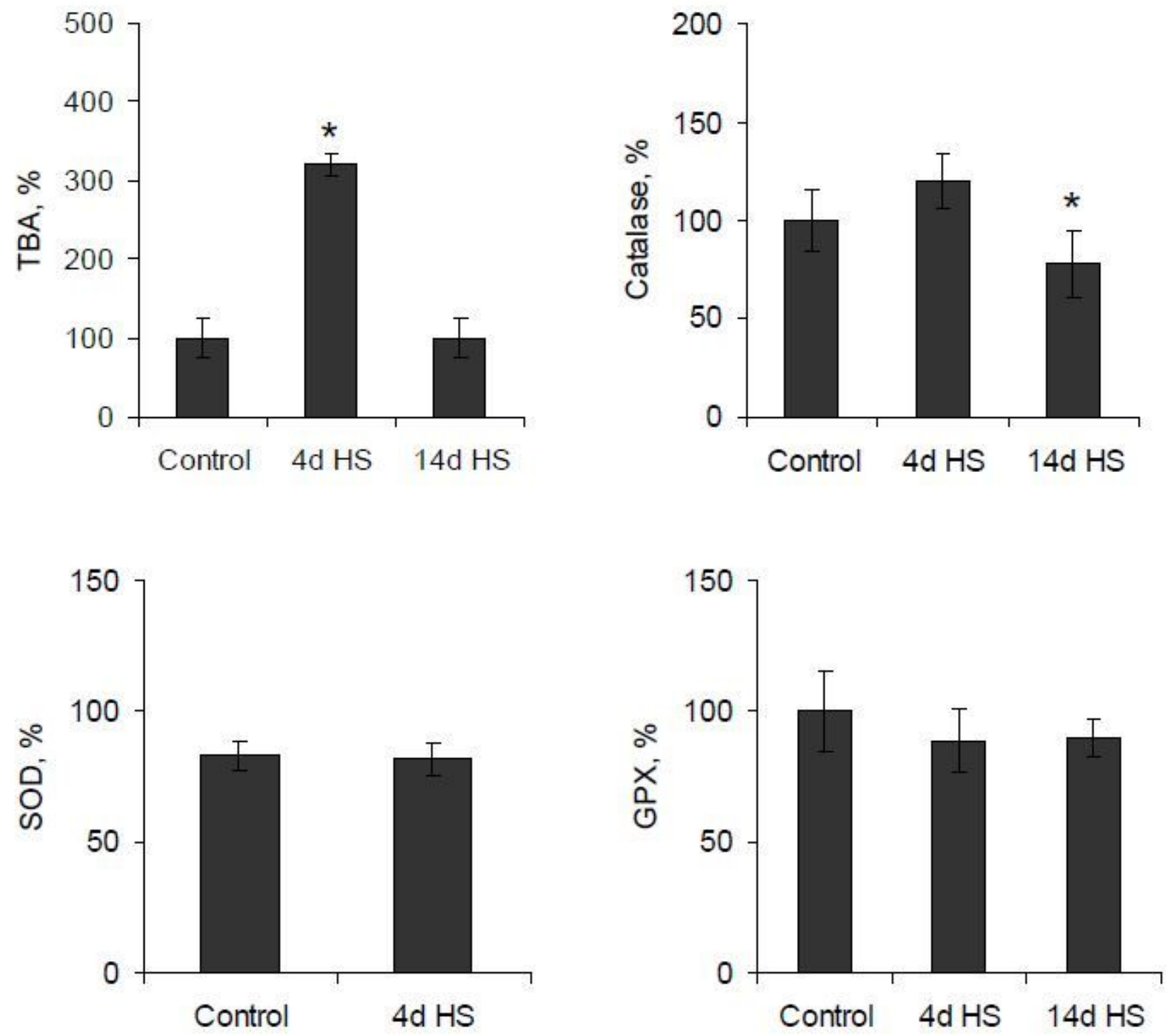

Figure 5

TBA-active products increase in rat soleus muscle after the 4-day unloading. Superoxide dismutase (SOD) and glutation peroxidase activities (GPx) did not change; catalase activity decreased in the muscle of rats subjected to 14-day HS; * - p<0.05 in comparison with the control values. 
Control
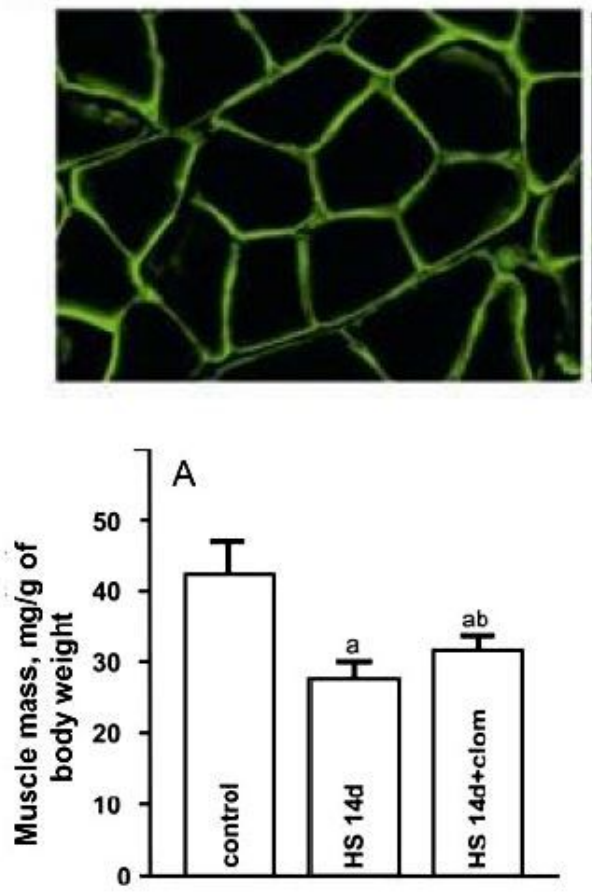

HS 14d
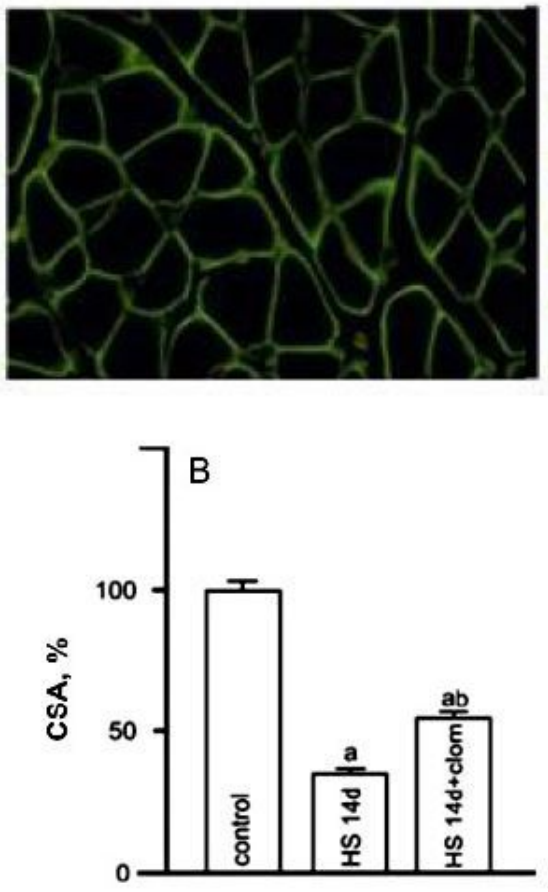

HS $14 d+$ clom
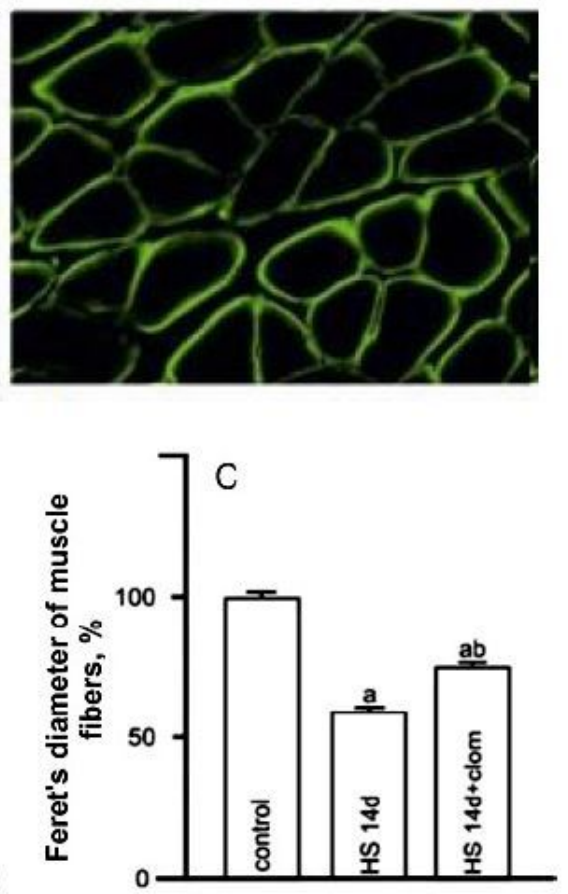

\section{Figure 6}

Loss of soleus muscle mass (A), decrease in cross-sectional area (CSA) and Feret's diameter (FD) of muscle fibers $(B, C)$ in rats suspended for 14 days. Clomipramine treatment of the suspended rats partly prevented muscle atrophy. The images of transverse sections of muscle fibers were obtained by staining with anti-caveolin-3 antibodies. Control - soleus muscle of the intact rat; HS 14d - unloaded muscle of the hindlimb suspended rat, HS 14d + clom - muscles of the rat suspended and treated with clomipramine.
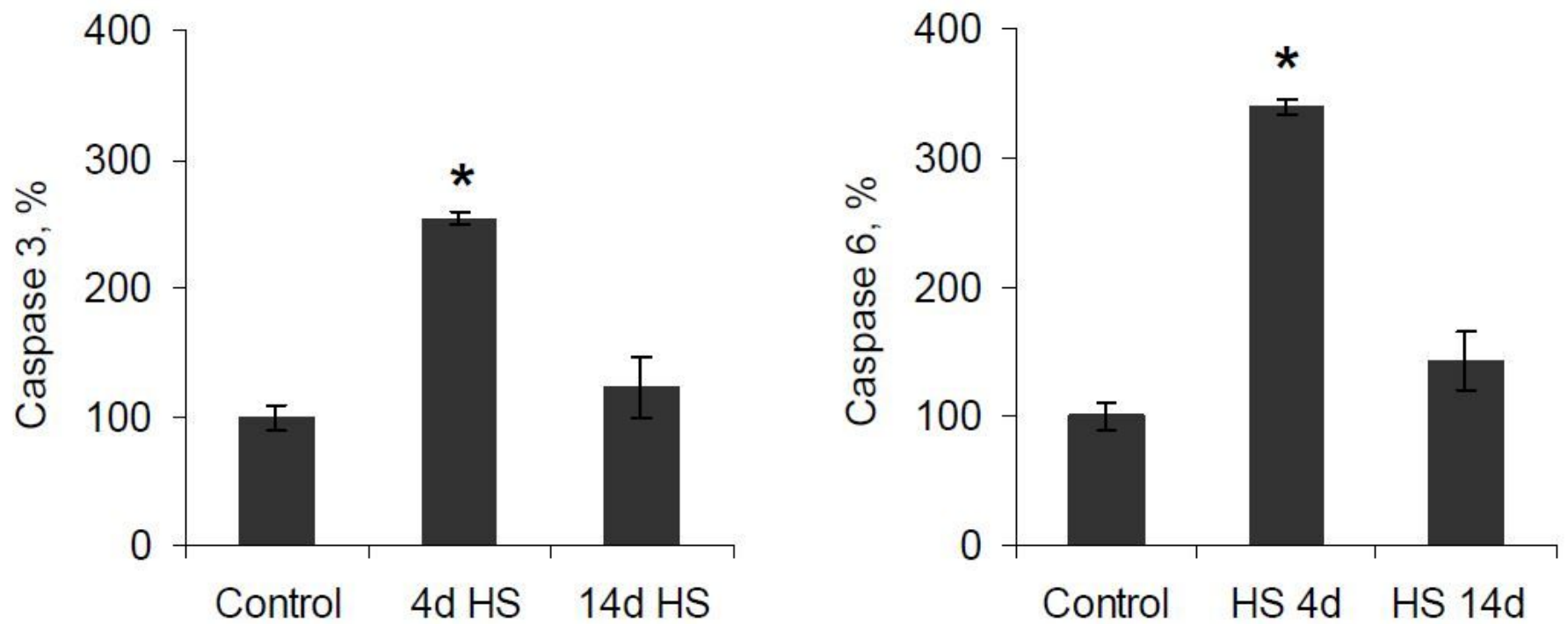
Figure 7

Caspase-3/7 and caspase- 6 activities enhanced on the 4th day of HS; * $-p<0.05$ in comparison with the control values.
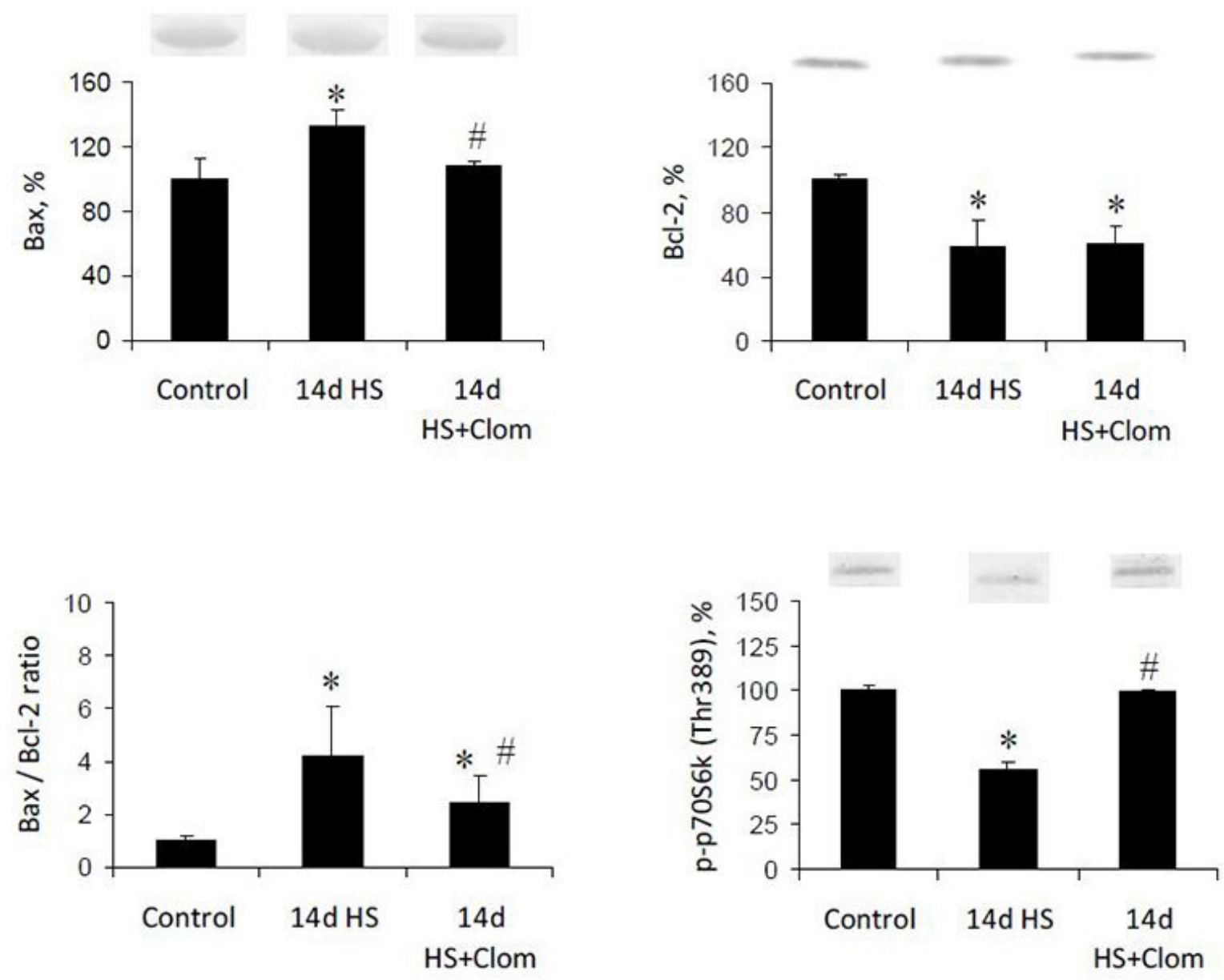

GAPDH

Control 14d HS HS+Clom

Figure 8 
Bax is up-regulated, $\mathrm{Bcl}-2$ and p-p70S6k (Thr389) are down-regulated in the soleus muscle disused for 14 days. Clomipramine treatment abolishes the enhancement of Bax and prevents the decrease in p70S6k (Thr389). * - $p<0.05$ in comparison with the control value, $\#-p<0.05$ in comparison with HS. 